\title{
Deep Eutectic Solvents as Catalysts for Upgrading Biomass
}

\author{
Payam Kalhor ${ }^{1}$ and Khashayar Ghandi ${ }^{2, *}$ (D) \\ 1 MOE Key Laboratory of Bioorganic Phosphorous Chemistry and Chemical Biology, Department of Chemistry, \\ Tsinghua University, Beijing 100084, China; baiy15@mails.tsinghua.edu.cn \\ 2 Department of Chemistry, University of Guelph, Guelph, ON N1G 2W1, Canada \\ * Correspondence: kghandi@uoguelph.ca; Tel.: +1-519-993-7312
}

check for updates

Citation: Kalhor, P.; Ghandi, K. Deep Eutectic Solvents as Catalysts for Upgrading Biomass. Catalysts 2021, 11, 178. https://doi.org/10.3390/ catal11020178

Academic Editors: Javier Bilbao Elorriaga, Idoia Hita Del Olmo and Peter J. Deuss

Received: 31 December 2020

Accepted: 25 January 2021

Published: 28 January 2021

Publisher's Note: MDPI stays neutral with regard to jurisdictional claims in published maps and institutional affiliations.

Copyright: (c) 2021 by the authors. Licensee MDPI, Basel, Switzerland. This article is an open access article distributed under the terms and conditions of the Creative Commons Attribution (CC BY) license (https:/ / creativecommons.org/licenses/by/ $4.0 /)$.

\begin{abstract}
Deep eutectic solvents (DESs) have emerged as promising green solvents, due to their versatility and properties such as high biodegradability, inexpensiveness, ease of preparation and negligible vapor pressure. Thus, DESs have been used as sustainable media and green catalysts in many chemical processes. On the other hand, lignocellulosic biomass as an abundant source of renewable carbon has received ample interest for the production of biobased chemicals. In this review, the state of the art of the catalytic use of DESs in upgrading the biomass-related substances towards biofuels and value-added chemicals is presented, and the gap in the knowledge is indicated to direct the future research.
\end{abstract}

Keywords: catalysis; deep eutectic solvent; biomass; biofuel; valorization

\section{Introduction}

In 2003, Abbott et al. proposed the concept of deep eutectic solvents (DESs) as a new generation of ionic liquid (IL) analogs, and probably the most novel class of solvents, composed of two or three components with a relatively large depression of melting points relative to those of the ideal liquid mixtures [1]. These components, performing the role of either hydrogen bond donors (HBDs) or hydrogen bond acceptors (HBAs) can be Lewis or Brønsted acids and bases involving a variety of neutral and ionic species [2]. The environmentally friendly properties of DESs such as low vapor pressure, recyclability and low toxicity have motivated research on the applications of DESs as alternative novel solvents to common organic ones [2,3]. DESs have found applications in several fields such as biofuel production [4,5], bio-oil production [6,7], catalysis [8-12], extraction [13-15] and separation processes [16,17].

They are easily prepared with usually no need for purification [3,18]. A remarkable property of DESs is the possibility to tailor the solvent in a task-specific way [2] and to a greater extent compared to ILs [19] that are already very good in this regard. This can be done by varying the molar ratio of the components, substituting a component with the one that brings the favorable property or by simply adding a specific amount of a cosolvent [20-22] such as water [23-26]. The DES-cosolvent preparation is especially important as most DESs have high viscosities [2] due to the extensive hydrogen bonding $(\mathrm{H}-$ bonding) networks [27,28] and van der Waals and electrostatic forces between species [29]. The high viscosity of the DESs can be mitigated via mixing with water [23-26]. However, care should be taken when diluting a DES with a cosolvent as the fundamental and desired properties of the DES may be affected by the cosolvent [25]. Most of the distinct properties of DESs are because of some specific underlying intermolecular interactions, with the most important one being the H-bonding. For instance, the significant decrease in the melting point of a typical DES is assumed to arise from the charge transfer between components, usually from the halide anion of an HBA to the HBD through H-bonds [22,26,30]. It has been found that as the H-bonds between HBD and HBA strengthen, the melting points depress more [1]. Depending on the DES constituents and their molar ratio, DESs may have reduced thermal stability [31-33]. 
The diminishing reserves of easily available fossil fuels and growing concerns about the global pollution as well as the upward demand for energy have significantly affected the research directions towards developing sustainable energy resources [34-44]. Therefore, inventive and appropriate uses of the naturally abundant supplies are important towards a sustainable future. As a very promising alternative to fossil fuels, biomass is increasingly drawing attention. Biomass is widely abundant, distributed worldwide and relatively inexpensive and has been used to produce various value-added chemicals [45-51]. Biomass transformation into valuable chemicals not only has revived the green chemistry principles but has also paved the way to alleviate the current high reliance on fossil fuels [48]. However, the optimization of chemical transformations towards a sustainable methodology and investigation of pivotal factors affecting process efficiency remain as challenges. Among all the factors affecting the conversion efficiency and the selectivity of the obtained products, the development and design of catalysts play a crucial role [52-59]. Catalysts have been regarded as important tools to accomplish a more sustainable chemical industry [56]. In this context, various catalytic systems have been proposed to produce upgraded chemicals and value-added products, with the purpose of drawing the full chemical potential of the biomass [11,53,55,60-62]. In recent years, DESs have been extensively used as active catalysts in valorization and upgrading of biomass in various types of reactions $[10,63]$ where they integrate the advantages of both homogenous and heterogeneous catalysts $[64,65]$. The catalytic DESs can dissolve a wide range of reactants and consequently change a heterogeneous catalytic mechanism into a homogeneous one [66].

The catalytic DESs can be categorized as either Lewis acid-type or Brønsted acid-type DESs [10]. The Lewis acid-type DESs consist of a few DESs, usually chlorides of transition metals such as $\mathrm{Zn}$ [67], $\mathrm{Fe}$ [68] and $\mathrm{Cr}$ [69] combined with mainly choline chloride (ChCl) in different molar ratios. On the other hand, there are diverse Brønsted acid-type DESs mostly containing $\mathrm{ChCl}$ combined with organic acids such as oxalic acid [70], citric acid [71], acetic acid [72], malonic acid [8], formic acid [73], $p$-toluene sulfonic acid ( $p$-TSA) [74] or alcohols such as ethylene glycol [75] or glycerol [76] or amides such as urea [77]. Figure 1 shows the general scheme for the conversion of biomass to value-added chemicals using catalytic biomass.

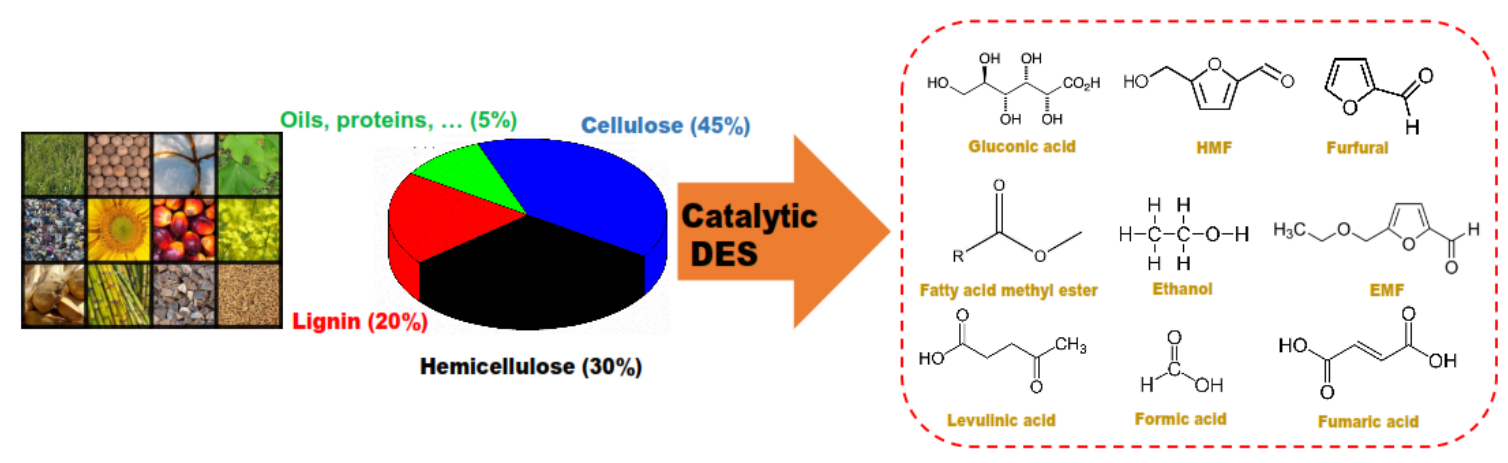

Figure 1. Conversion of biomass to value-added chemicals using catalytic deep eutectic solvents (DESs).

This review focuses on the applications of DESs as catalysts in upgrading biomass. The review consists of the following parts. Section 2: Recent research on the applications of the catalytic DESs in upgrading biomass-based on the constituents, these catalysts are discussed in two separate classes of Lewis acid-type DESs and Brønsted acid-type DESs. Section 3: Recyclability of the catalytic DESs. Section 4: Limitations of DESs. Section 5: Conclusions and future prospects. 


\section{Catalytic Application of Deep Eutectic Solvents in Upgrading Biomass}

Table 1 lists a collection of processes where DESs are employed as either Lewis acidtype or Brønsted acid-type catalysts to convert biomass to value-added chemicals.

\subsection{Processes Catalyzed by Lewis Acid-Type DESs}

Lewis acid-based transition-metal chlorides can catalytically activate the electronrich substrates due to their electron deficiency [78]. The DESs containing metal chlorides are Lewis acidic. In catalytic upgrading of biomass, there are a few cases with catalytic DESs composed of metal chlorides. However, the most widely used metal chlorides are $\mathrm{ZnCl}_{2}$ [67], $\mathrm{FeCl}_{3}$ [68], $\mathrm{CrCl}_{3}$ [69], $\mathrm{MnCl}_{2}$ [77] and $\mathrm{CuCl}_{2}$ [77] to form DESs often with $\mathrm{ChCl}$. This part discusses the application of DESs as Lewis acid catalysts in biomass conversion.

Long et al. [67] studied the transesterification of soybean oil to biodiesel using $\left(\mathrm{ChCl}: x \mathrm{ZnCl}_{2}\right)$ DES as the catalyst, where methanol was used as a solvent. They found that the strength of the Lewis acidity of the DES increased upon increase of $x$. They suggested that $\mathrm{Zn}_{2} \mathrm{Cl}_{5}{ }^{-}$mainly catalyzed the transesterification, as $\mathrm{Zn}_{2} \mathrm{Cl}_{5}{ }^{-}$was the predominant species in the mixture. However, the yield of biodiesel was not satisfying because of the weak acidity of $\mathrm{Zn}_{2} \mathrm{Cl}_{5}{ }^{-}$. With the addition of $10 \%\left(\mathrm{ChCl}: 2 \mathrm{ZnCl}_{2}\right)$ catalyst and a $16: 1$ molar ratio of methanol to soybean oil, the conversion rate reached $54.52 \%$ after $72 \mathrm{~h}$ at $70{ }^{\circ} \mathrm{C}$. Finally, they proposed the transesterification mechanism as shown in Figure 2.

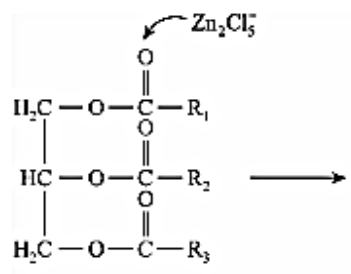

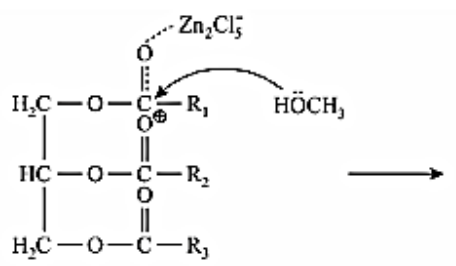

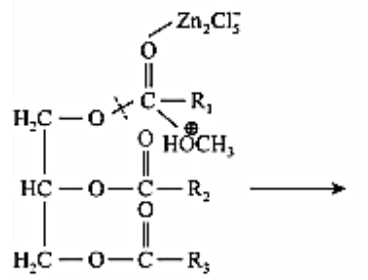

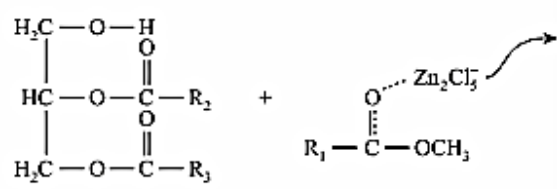

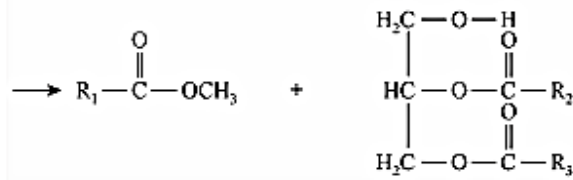

Figure 2. The proposed transesterification mechanism. Reprinted from reference [67] with permission.

Mondal et al. [68] produced $\mathrm{Fe}_{3} \mathrm{O}_{4} / \mathrm{Fe}$-doped graphene nanosheets (GNs) by pyrolysis of granules of seaweed biomass and used $\left(\mathrm{ChCl}: \mathrm{FeCl}_{3}\right)$ DES as catalyst. The reaction was performed at $700-900{ }^{\circ} \mathrm{C}$ under an atmosphere of $95 \% \mathrm{~N}_{2}$ and $5 \% \mathrm{H}_{2}$. The resulted $\mathrm{Fe}_{3} \mathrm{O}_{4} / \mathrm{Fe}$-doped GN had favorable properties such as high surface area $\left(220 \mathrm{~m}^{2} \cdot \mathrm{g}^{-1}\right)$ and high electrical conductivity $\left(2384.6 \mathrm{mS} \cdot \mathrm{m}^{-1}\right)$. It was found that the nanosheets had highly stable oxygen reduction reaction (ORR) electrocatalytic activity after 30,000 cycles. This would make the produced graphene sheets a sustainable substitution for the existing catalysts composed of expensive metal-based ORRs. Figure 3 displays the proposed flowchart for production of $\mathrm{Fe}_{3} \mathrm{O}_{4} / \mathrm{Fe}-\mathrm{GN}$ from Sargassum tenerrimum biomass. 
Table 1. Catalytic DESs used in biomass upgrading.

\begin{tabular}{|c|c|c|c|c|c|}
\hline DES & Feedstock & Process & Conditions/Results & DES Recyclability & Ref. \\
\hline \multicolumn{6}{|c|}{ Lewis acid-type DESs } \\
\hline $\mathrm{ChCl}: 2 \mathrm{FeCl}_{3}$ & Bagasse lignin & Fractionation of lignin & $\begin{array}{c}74 \% \text { selectivity for methyl } \\
p \text {-hydroxycinnamate, after } 8 \mathrm{~h} \text {, at } 160^{\circ} \mathrm{C} \text {. }\end{array}$ & 6 runs & [80] \\
\hline $\begin{array}{l}\mathrm{ChCl}: \mathrm{ZnCl}_{2} \\
\mathrm{ChCl}: 2 \mathrm{ZnCl}_{2} \\
\mathrm{ChCl}: 3 \mathrm{ZnCl}_{2}\end{array}$ & Soybean oil & $\begin{array}{l}\text { Transesterification of soybean oil } \\
\text { to biodiesel }\end{array}$ & $\begin{array}{l}55 \% \text { transesterification yield. } 16: 1, \\
\text { Methanol: oil ratio. }\left(\mathrm{ChCl}: 2 \mathrm{ZnCl}_{2}\right) \text { DES } \\
10 \% \text { at } 70{ }^{\circ} \mathrm{C} \text { for } 72 \mathrm{~h} .\end{array}$ & Unable to recycle & [67] \\
\hline $\mathrm{ChCl}: 2 \mathrm{FeCl}_{3}$ & Seaweed & $\begin{array}{l}\text { Production of } \mathrm{Fe}_{3} \mathrm{O}_{4} / \mathrm{Fe} \text {-doped } \\
\text { graphene nanosheets (GNs) } \\
\text { from seaweed }\end{array}$ & $\begin{array}{l}\text { Formation of } \mathrm{Fe}_{3} \mathrm{O}_{4} / \mathrm{Fe}-\mathrm{GN} \text { with high } \\
\text { surface area and electrical conductivity } \\
\text { under } 95 \% \mathrm{~N}_{2} \text { and } 5 \% \mathrm{H}_{2}, \text { pyrolysis of } \\
\text { DES + seaweed at } 700-900{ }^{\circ} \mathrm{C}\end{array}$ & Not reported & [68] \\
\hline 10dimethylurea: $3 \mathrm{ZnCl}_{2}$ & Cellulose & $\begin{array}{l}\text { Synthesis of cellulose methyl } \\
\text { carbamate }(\mathrm{CMeC})\end{array}$ & $\begin{array}{l}\text { The degree of substitution was } 0.17 \text { after } \\
3 \mathrm{~h} \text { of reaction at } 150{ }^{\circ} \mathrm{C} .\end{array}$ & Not reported & [79] \\
\hline $\begin{array}{l}\mathrm{FeCl}_{3} \cdot 6 \mathrm{H}_{2} \mathrm{O} \text {-based DESs } \\
\quad \text { (different ratios) }\end{array}$ & Cellulose & $\begin{array}{l}\text { Conversion of cellulose to } \\
\text { gluconic acid }\end{array}$ & $\begin{array}{l}2 \mathrm{FeCl}_{3} \cdot 6 \mathrm{H}_{2} \mathrm{O} \text { :ethylene glycol DES } \\
\text { provided the highest yield ( } 53 \% \text { ) of } \\
\text { gluconic acid at } 120{ }^{\circ} \mathrm{C} \text { for } 60 \mathrm{~min} .\end{array}$ & $\begin{array}{c}5 \text { runs } \\
\left(\mathrm{FeCl}_{3} \cdot 6 \mathrm{H}_{2} \mathrm{O} \text { :ethylene }\right. \\
\text { glycol })\end{array}$ & [66] \\
\hline $\begin{array}{l}\text { ChCl:4.43oxalic acid } \cdot 2 \mathrm{H}_{2} \mathrm{O}: \\
0.1 \mathrm{FeCl}_{3} \cdot 6 \mathrm{H}_{2} \mathrm{O}\end{array}$ & $\begin{array}{c}\text { Bleached } \\
\text { eucalyptus Kraft pulp (BEKP) }\end{array}$ & $\begin{array}{l}\text { Fabricate cellulose nanocrystals } \\
\text { (CNCs) from BEKP }\end{array}$ & $\begin{array}{l}\text { The yield of CNCs was higher than } 90 \% \\
\text { under mild conditions, i.e., } 80^{\circ} \mathrm{C} \text { and } 6 \mathrm{~h} \text {. }\end{array}$ & 3 runs & [82] \\
\hline \multicolumn{6}{|c|}{ Brønsted acid-type DESs } \\
\hline ChCl:oxalic acid & Corncob & Change corncob to furfuryl alcohol & $\begin{array}{l}46 \% \text { furfural alcohol yield at } 120{ }^{\circ} \mathrm{C} \text { for } \\
\qquad 30 \mathrm{~min} .\end{array}$ & 3 runs & [83] \\
\hline ChCl:p-TSA ${ }^{2}$ & Alkali lignin & $\begin{array}{l}\text { Degradation of alkali lignin (cleavage } \\
\text { of } \beta-O-4 \text { ) }\end{array}$ & $\begin{array}{c}\text { At } 130{ }^{\circ} \mathrm{C} \text {, the content of phenolic } \\
\text { hydroxyl species increased. Alakali lignin } \\
\text { underwent decarbonylation } \\
\text { during treatment. }\end{array}$ & Not reported & [84] \\
\hline
\end{tabular}


Table 1. Cont.

\begin{tabular}{|c|c|c|c|c|c|}
\hline DES & Feedstock & Process & Conditions/Results & DES Recyclability & Ref. \\
\hline $\begin{array}{c}\mathrm{ChCl}: 2 \text { urea } \\
\mathrm{ChCl}: 2 \mathrm{ZnCl}_{2} \\
\mathrm{ChCl}: 2 \mathrm{CrCl}_{3} \cdot \\
6 \mathrm{H}_{2} \mathrm{O} \\
\mathrm{ChCl} \text { :malonic acid } \\
\mathrm{ChCl} \text { :oxalic acid } 2 \mathrm{H}_{2} \mathrm{O} \\
2 \mathrm{ChCl} \text { :citric acid } \cdot \mathrm{H}_{2} \mathrm{O} \\
\text { 2ChCl:citric acid }\end{array}$ & Fructose & $\begin{array}{c}\text { Conversion of fructose to } \\
\text { hydroxymethylfurfural (HMF) }\end{array}$ & $\begin{array}{l}\text { Most DESs were effective to convert } \\
\text { fructose ( } 91-100 \%) \text {. The Lewis acid-based } \\
\text { DESs were not efficient to produce HMF. } \\
\text { More than } 90 \% \text { of fructose conversion was } \\
\text { obtained with ChCl:malonic acid/oxalic } \\
\text { acid/citric acid } \cdot \mathrm{H}_{2} \mathrm{O} \text { at } 80{ }^{\circ} \mathrm{C} \text { for } 1 \mathrm{~h}\end{array}$ & $\begin{array}{l}8 \text { runs }(2 \mathrm{ChCl} \text { :citric } \\
\left.\text { acid } \cdot \mathrm{H}_{2} \mathrm{O}\right)\end{array}$ & [69] \\
\hline $\begin{array}{l}\text { ChCl:oxalic acid } \cdot 2 \mathrm{H}_{2} \mathrm{O} \\
\text { 2ChCl:citric acid } \cdot \mathrm{H}_{2} \mathrm{O}\end{array}$ & Inulin & Conversion of inulin to HMF & $\begin{array}{l}\text { Using }\left(\mathrm{ChCl} \text { : oxalic acid } \cdot 2 \mathrm{H}_{2} \mathrm{O}\right) \text { and } \\
\left(2 \mathrm{ChCl} \text { : citric acid. } \mathrm{H}_{2} \mathrm{O}\right), \text { at } 80^{\circ} \mathrm{C} \text { for } 2 \mathrm{~h} \text {, } \\
\text { the yields of } \mathrm{HMF} \text { were } 64 \text { and } 57 \% \text {, } \\
\text { respectively. }\end{array}$ & $\begin{array}{l}6 \text { runs }(\mathrm{ChCl} \text { :oxalic } \\
\left.\text { acid } 2 \mathrm{H}_{2} \mathrm{O}\right)\end{array}$ & [70] \\
\hline АТРPВ $^{1}: 3 p-$ TSA $^{2}$ & $\begin{array}{l}\text { Low-grade crude palm oil } \\
\text { (LGCPO) }\end{array}$ & $\begin{array}{l}\text { Biodiesel production from LGCPO via } \\
\text { esterification process }\end{array}$ & $\begin{array}{l}\text { The esterification in } 1 \mathrm{wt} \% \text { DES, } 10: 1 \\
\text { methanol to LGCPO, at } 60^{\circ} \mathrm{C} \text { in } 30 \mathrm{~min} \text {. } \\
<2 \% \text { free fatty acid (FFA). }\end{array}$ & 4 runs & [85] \\
\hline $2 \mathrm{ChCl}$ :citric acid $\cdot \mathrm{H}_{2} \mathrm{O}$ & Xylan and xylose & $\begin{array}{l}\text { Conversion of xylan and xylose to } \\
\text { furfural, co-catalyzed by the DES and } \\
\text { metal chlorides }\end{array}$ & $\begin{array}{l}\text { In monophasic approach (DES + metal } \\
\text { chloride), furfural yield from xylose and } \\
\text { xylan were } 59 \text { and } 54 \% \text {, respectively. The } \\
\text { yields increased to } 73.1 \text { and } 67 \% \text { in } \\
\text { biphasic system (DES + metal chloride + } \\
\text { methyl isobutyl ketone (MIBK)). }\end{array}$ & 5 runs & [71] \\
\hline $\mathrm{DEACl}^{3}: 3 p-\mathrm{TSA}^{2}$ & Crude palm oil & $\begin{array}{l}\text { Decreasing the level of FFAs for } \\
\text { biodiesel production }\end{array}$ & $\begin{array}{l}\text { The FFAs were reduced to }<1 \% \text {. The DES: } \\
\text { palm oil was } 0.75 \%(\mathrm{wt} / \mathrm{wt}) \text {. Methanol:oil } \\
\text { ratio was } 8: 1 \text { at } 60^{\circ} \mathrm{C} \text { for } 30 \mathrm{~min} \text {. }\end{array}$ & 4 runs & [86] \\
\hline $\mathrm{ChCl}: 3 p-\mathrm{TSA}^{2}$ & $\begin{array}{l}\text { Acidic crude palm oil } \\
\text { (ACPO) }\end{array}$ & $\begin{array}{l}\text { Biodiesel production from ACPO } \\
\text { (conversion of FFAs in ACPO to fatty } \\
\text { acid methyl esters (FAME)) }\end{array}$ & $\begin{array}{l}\text { The 1:10 molar ratio of Methanol:oil with } \\
0.75 \text { mass ratio of DES:ACPO reduced } \\
\text { FFAs to }<1 \% \text { at } 60^{\circ} \mathrm{C} \text { in } 30 \mathrm{~min} \text {. }\end{array}$ & 3 runs & [87] \\
\hline ChCl:oxalic acid & Xylose and xylan & $\begin{array}{l}\text { Furfural production from xylose and } \\
\text { xylan using monophasic (DES) or } \\
\text { biphasic (DES + MIBK) systems }\end{array}$ & $\begin{array}{l}\text { Addition of metal chlorides to the DES led } \\
\text { to improved furfural yields (14- } 44 \% \text { ). In } \\
\text { the biphasic procedure, the yields from } \\
\text { xylose and xylan were, respectively, } 60 \text { and } \\
56 \% \text { in } \mathrm{AlCl}_{3} \cdot 6 \mathrm{H}_{2} \mathrm{O} \text { presence. }\end{array}$ & 5 runs & [88] \\
\hline
\end{tabular}


Table 1. Cont.

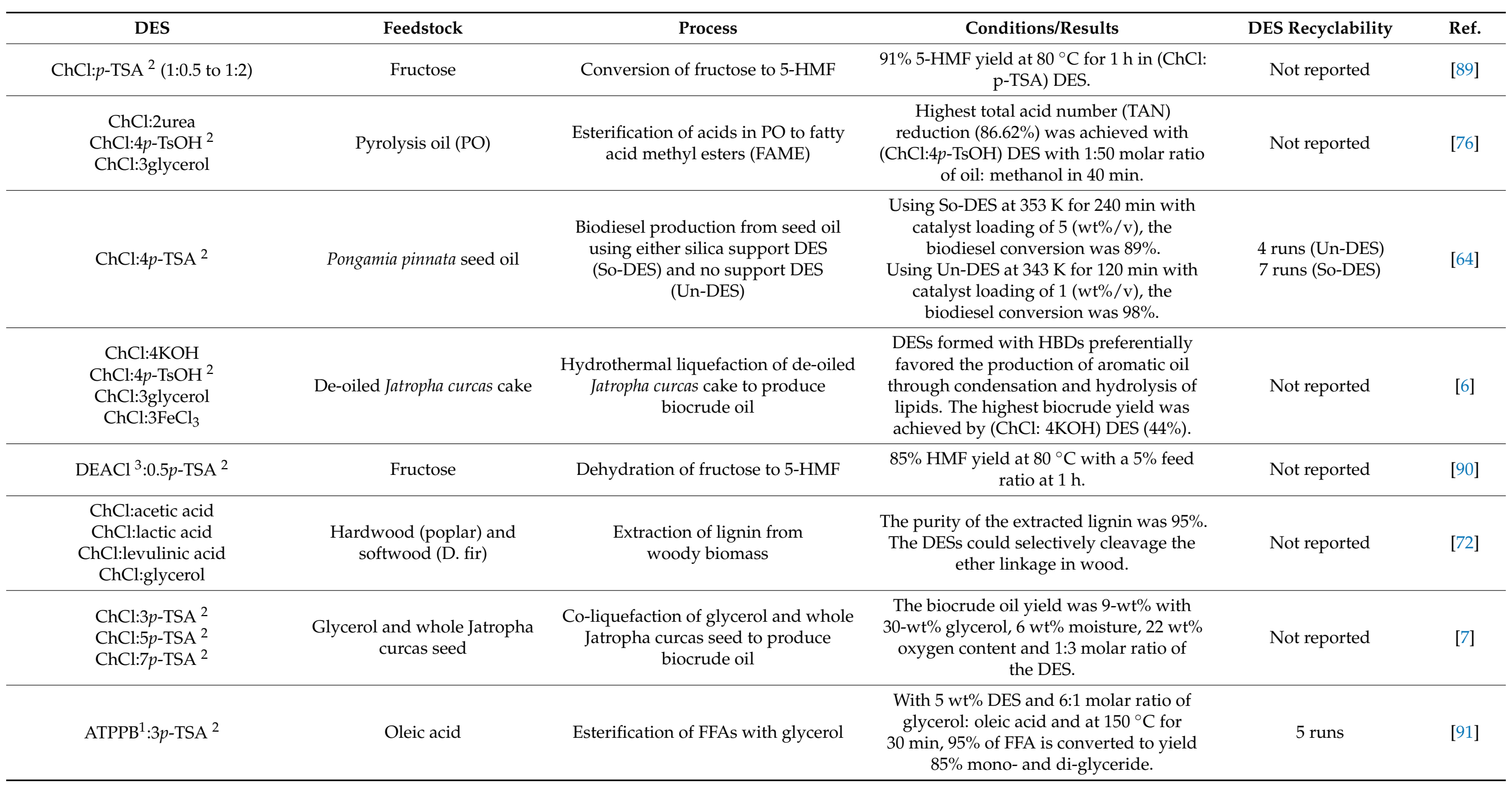


Table 1. Cont.

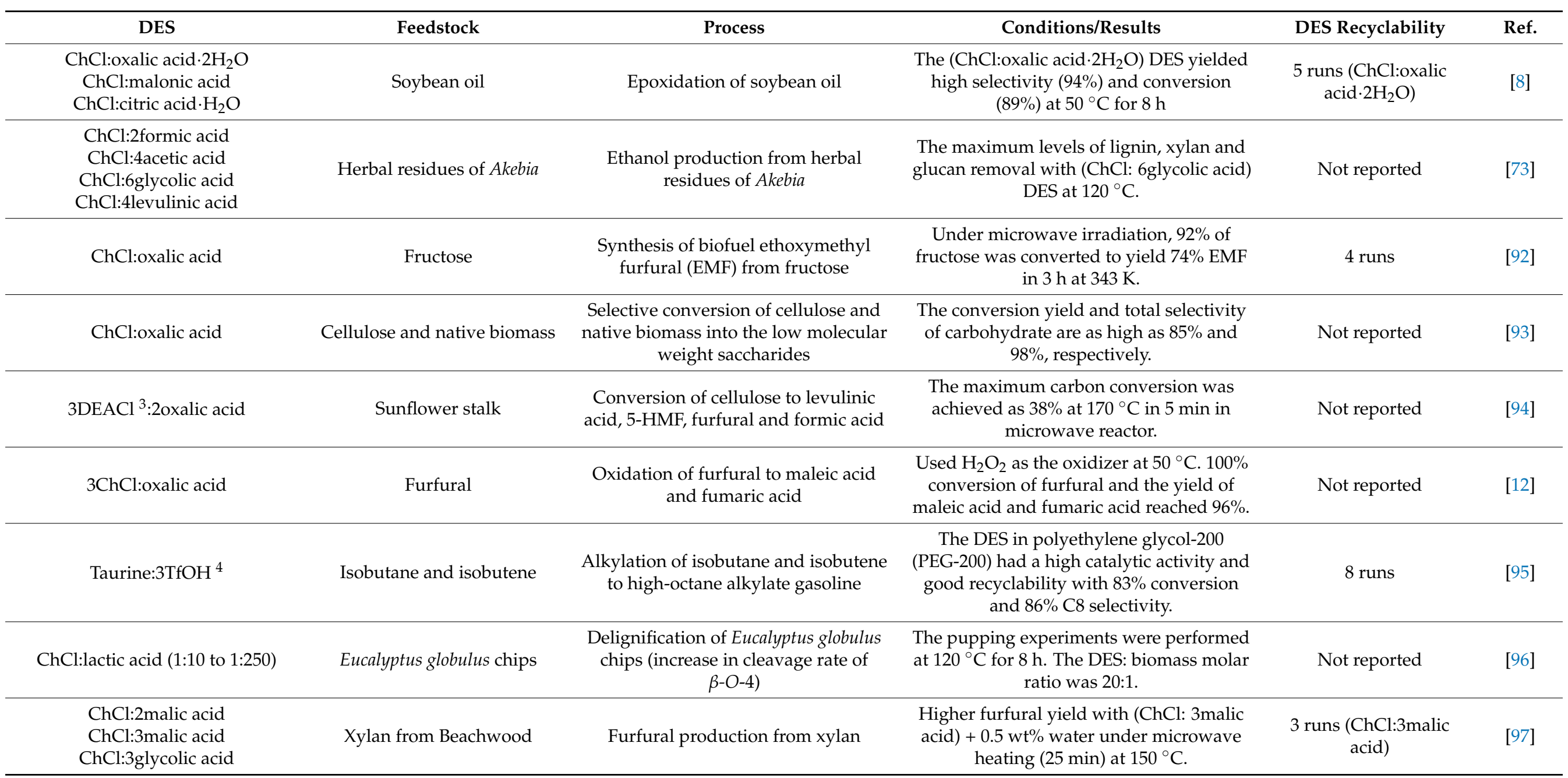


Table 1. Cont.

\begin{tabular}{|c|c|c|c|c|c|}
\hline DES & Feedstock & Process & Conditions/Results & DES Recyclability & Ref. \\
\hline $\begin{array}{l}\mathrm{TPAB}^{5}: 4 \text { ethylene glycol } \\
\mathrm{ChCl} \text { 2ethylene glycol }\end{array}$ & $\begin{array}{c}\text { Heavy residual } \\
\text { Fuel oil (Mazut280) }\end{array}$ & Upgrading Mazut280 to light fuels & $\begin{array}{l}\text { (TPAB:4ethylene glycol) DES was more } \\
\text { efficient than (ChCl: 2ethylene glycol) DES } \\
\text { with higher asphaltene reduction and } \\
\text { desulfurization, resulting in high and } \\
\text { stable light oil. }\end{array}$ & Not reported & [98] \\
\hline $\begin{array}{l}\text { betaine: oxalic acid } \cdot 2 \mathrm{H}_{2} \mathrm{O} \\
\quad(1: 1 \text { to } 1: 28)\end{array}$ & $\alpha$-pinene & Hydration of $\alpha$-pinene to $\alpha$-terpineol & $\begin{array}{c}\text { The 1:2.7 molar ratio of the DES achieved } \\
\text { the best catalytic and recyclability } \\
\text { performance. }\end{array}$ & 5 runs & [99] \\
\hline 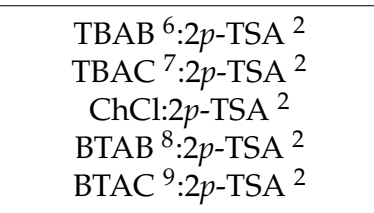 & Yellow horn seed & $\begin{array}{l}\text { Biodiesel production from the yellow } \\
\text { horn seed via extraction of oil and } \\
\text { conversion of fatty acid methyl esters }\end{array}$ & $\begin{array}{l}11 \mathrm{wt} \% \text { of (TBAB: } 2 \mathrm{p}-\mathrm{TSA}) \text { DES exhibited } \\
\text { the best catalytic activity with the } \\
\text { maximum oil extraction }(90 \%) \text { and fatty } \\
\text { acid conversion }(97 \%) \text { at } 72^{\circ} \mathrm{C} \text { for } 40 \text { min. }\end{array}$ & 5 runs (TBAB: $2 p-\mathrm{TSA})$ & [74] \\
\hline $\begin{array}{c}\text { ChCl:urea }(1: 1 \text { to } 1: 4) \\
\text { ChCl:oxalic acid } \\
\text { ChCl:benzoic acid } \\
\text { ChCl:p-TSA }{ }^{2} \\
\text { ChCl:2} \mathrm{MnCl}_{2} \\
\text { ChCl:2CuCl } \\
\text { ChCl:2acetamide }\end{array}$ & Polycarbonate & $\begin{array}{c}\text { Methanolysis of polycarbonate to } \\
\text { obtain bisphenol A }\end{array}$ & $\begin{array}{l}\text { The most effective catalyst was } \\
\text { (ChCl:2urea) DES with } \sim 100 \% \\
\text { polycarbonate conversion at } 130{ }^{\circ} \mathrm{C} \text { for } \\
2.5 \mathrm{~h} \text {. }\end{array}$ & 5 runs (ChCl:2urea) & [77] \\
\hline $\begin{array}{l}\text { urea:2propionic acid } \\
\text { ChCl:10lactic acid } \\
\text { ChCl:p-TSA }{ }^{2}\end{array}$ & $\begin{array}{l}\text { 2-phenoxy-1- phenyl ethanol } \\
\text { (PPE) (a lignin model } \\
\text { compound) }\end{array}$ & $\begin{array}{l}\text { Cleavage of the } \\
\beta-O-4 \text { ether bond in the model biomass }\end{array}$ & $\begin{array}{l}\text { (ChCl: } p \text {-TSA) demonstrated the highest } \\
\text { performance in the PPE cleavage. }\end{array}$ & Not reported & [100] \\
\hline imidazole:1.5BSA ${ }^{10}$ & Fructose & Dehydration of fructose to 5-HMF & $\begin{array}{l}\text { The } 5 \text {-HMF yield was } 90.1 \% \text { at } 100^{\circ} \mathrm{C} \text { in } \\
\qquad 3 \mathrm{~min} .\end{array}$ & 1 run & [101] \\
\hline АТРPВ $^{1}: 3 p-$ TSA $^{2}$ & $\begin{array}{l}\text { Vegetable oil deodorizer } \\
\text { distillate }\end{array}$ & $\begin{array}{l}\text { Esterification of FFA in vegetable oil } \\
\text { into glycerides }\end{array}$ & $\begin{array}{l}\text { Glycerolysis reaction reached equilibrium } \\
\text { at FFA conversion of } 90 \% \text {. The optimum } \\
\text { condition was determined at } 160^{\circ} \mathrm{C} \text {, } \\
5 \mathrm{wt} \% \text { of DES in } 10 \mathrm{~min} .\end{array}$ & Not reported & [102] \\
\hline
\end{tabular}


Table 1. Cont

\begin{tabular}{|c|c|c|c|c|c|}
\hline DES & Feedstock & Process & Conditions/Results & DES Recyclability & Ref. \\
\hline $\mathrm{ChCl}$ :2oxalic acid & Cotton fiber & Production of CNCs from cotton fiber & $\begin{array}{l}\text { The used DES showed a high recyclability } \\
\qquad(>85 \%) .\end{array}$ & 5 runs & [103] \\
\hline $\begin{array}{l}\text { ChCl:2acetic acid } \\
\text { ChCl:malonic acid } \\
\text { ChCl:oxalic acid } \\
\text { ChCl:citric acid } \\
\text { ChCl:2formic acid } \\
\text { 3ChCl:7p-TSA }{ }^{2}\end{array}$ & Levulinic acid & $\begin{array}{l}\text { Esterification of levulinic acid to } \\
\text { produce ethyl levulinate }\end{array}$ & $\begin{array}{l}\text { The most active catalyst: (3ChCl:7p-TSA) } \\
\text { DES. } 100 \% \text { yield with } 5 \text {-wt } \% \text { of the DES } \\
\text { at } 353 \mathrm{~K} \text { for } 1 \mathrm{~h} \text {. }\end{array}$ & Not reported & [65] \\
\hline $\mathrm{ChCl}$ :8formic acid & Furfural, xylose and corncob & $\begin{array}{l}\text { Synthesis of cyclic biofuel } \\
\text { intermediates }\end{array}$ & $\begin{array}{c}\text { The direct conversion of furfural, xylose, } \\
\text { and corncob to cyclic biofuel intermediates } \\
\text { were as high as } 92,88 \text {, and } 57 \% \text {, } \\
\text { respectively. }\end{array}$ & Not reported & [104] \\
\hline $\begin{array}{l}\mathrm{ChCl} \text { :2ethylene glycol }\left(\mathrm{CrCl}_{3} \text { had }\right. \\
\text { synergistic catalytic effect with } \\
\text { ChCl) }\end{array}$ & Glucose & Dehydration of glucose to 5-HMF & $\begin{array}{c}\text { At } 150{ }^{\circ} \mathrm{C} \text { for } 3.64 \mathrm{~min} \text {, the yield of } 5-\mathrm{HMF} \\
\text { reached } 42 \% \text {. }\end{array}$ & 4 runs & [75] \\
\hline $\mathrm{ChCl}$ :2lactic acid & $\begin{array}{l}\text { Isolated lignin from } \\
\text { Eucalyptus tree and a series of } \\
\beta-O-4 \text { lignin model } \\
\text { compounds }\end{array}$ & $\begin{array}{c}\text { The } \beta-O-4 \text { bonds in either realistic } \\
\text { lignin } \\
\text { or model compounds were cleaved by } \\
\text { the DES }\end{array}$ & $\begin{array}{l}\text { Increase of the reaction temperature and } \\
\text { time resulted in a decrease of insoluble } \\
\text { lignin fraction and average molecular } \\
\text { weights, as well as a sustained increase of } \\
\text { hydroxyl groups. }\end{array}$ & 1 run & [105] \\
\hline ChCl:10lactic acid & Eucalyptus & $\begin{array}{l}\text { Depolymerization of the double } \\
\text { enzymatic lignin (DEL) via a novel } \\
\text { biorefinery process }\end{array}$ & $\begin{array}{l}\text { DES pretreatment in } 60-140^{\circ} \mathrm{C} \text { for } 6 \mathrm{~h}: \\
\text { cleavage of } \mathrm{C}-\mathrm{O} \text { and } \mathrm{C}-\mathrm{C} \text { bonds in the } \\
\text { lignin, dehydration, and acylation of } \\
\text { hydroxyl groups of lignin, and } \\
\text { recondensation of lignin. }\end{array}$ & Not reported & [106] \\
\hline $\begin{array}{l}\text { ChCl:oxalic acid } \\
\text { ChCl:2glycerol }\end{array}$ & Moso bamboo & $\begin{array}{l}\text { Extraction of phenolic lignin from } \\
\text { bamboo by subcritical ethanol } \\
\text { catalyzed by DES }\end{array}$ & $\begin{array}{l}\text { At } 160^{\circ} \mathrm{C} \text {, the }(\mathrm{ChCl} \text { : oxalic acid) DES } \\
\text { obtained lignin with high UV-blocking } \\
\text { and high phenolic hydroxyl content. }\end{array}$ & Not reported & [107] \\
\hline
\end{tabular}


Table 1. Cont.

\begin{tabular}{|c|c|c|c|c|c|}
\hline DES & Feedstock & Process & Conditions/Results & DES Recyclability & Ref. \\
\hline $\begin{array}{c}\text { ChCl:oxalic acid } \\
\text { 2ChCl:oxalic acid: } p \text {-TSA }{ }^{2}\end{array}$ & $\begin{array}{l}\text { Softwood thermomechanical } \\
\text { pulp (TMP) }\end{array}$ & $\begin{array}{l}\text { Lignin-containing cellulose } \\
\text { nanocrystals } \\
\text { (LCNCs) from TMP }\end{array}$ & $\begin{array}{l}\text { LCNCs were isolated from DESs, showing } \\
\text { a higher yield }(66 \%) \text { when using the } \\
\text { ternary DES }(3 \mathrm{~h}) .\end{array}$ & Not reported & [108] \\
\hline $\begin{array}{l}\text { ChCl:2formic acid } \\
\text { ChCl:2acetic acid } \\
\text { ChCl:2lactic acid }\end{array}$ & Poplar wood shavings & $\begin{array}{c}\text { Extraction of lignin from Poplar } \\
\text { biomass and enhance cellulose } \\
\text { reactivity }\end{array}$ & $\begin{array}{c}6.3-7.9 \% \text { lignin selectivity \& } \\
\text { delignification (73-77\%) along with } \\
\text { increase in the available area and porosity } \\
\text { of cellulose were achieved. }\end{array}$ & Not reported & [110] \\
\hline $\mathrm{TOAB}^{11}: 2 p-\mathrm{TsOH}^{2}$ & $\begin{array}{l}\text { Cooked and waste } \\
\text { vegetable oils }\end{array}$ & $\begin{array}{l}\text { Transesterification of the cooked and } \\
\text { waste vegetable oils into biodiesel }\end{array}$ & $\begin{array}{l}\text { The catalytic DES enhanced the direct } \\
\text { contact between MeOH and oil. The yield } \\
\text { of FAME was } 99 \% \text { at } 70.5^{\circ} \mathrm{C} \text {, DES dosage } \\
\text { of } 24.6 \mathrm{wt} \% \text { and a molar ratio of } 12.5 \text {. }\end{array}$ & 5 runs & [111] \\
\hline
\end{tabular}

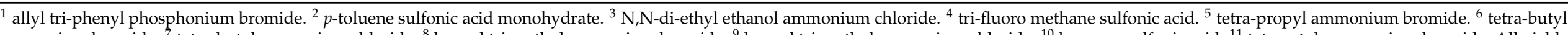

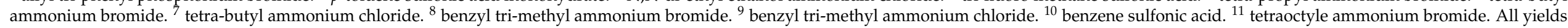
were rounded to the nearest integer. 


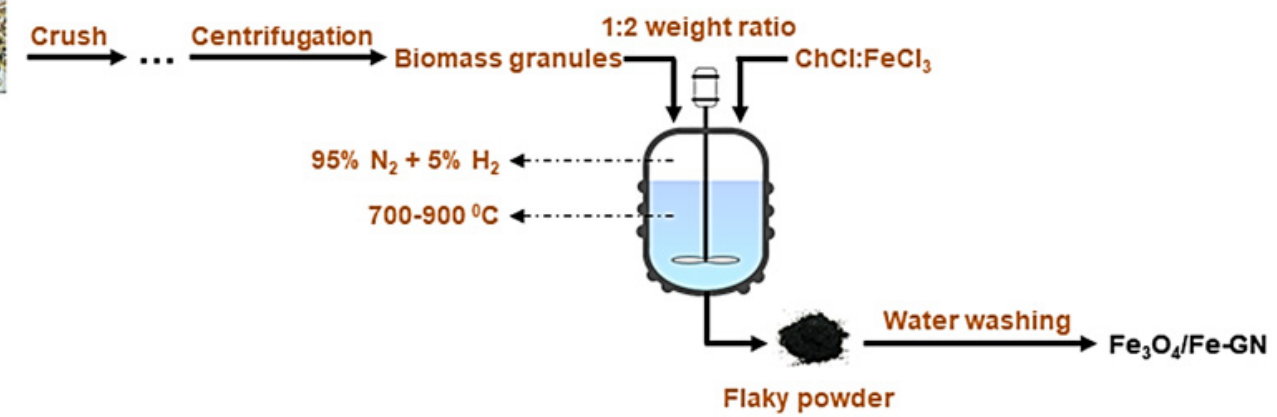

Figure 3. The flowchart for production of $\mathrm{Fe}_{3} \mathrm{O}_{4} / \mathrm{Fe}-\mathrm{GN}$ from Sargassum tenerrimum biomass.

The Lewis acid-type DESs have also been employed as catalysts for chemical modifications of cellulose to value-added chemicals. For example, Sirvio et al. [79] found that a reactive DES composed of dimethyl-urea and $\mathrm{ZnCl}_{2}$ (10:3) could be used to synthesize cellulose methyl carbamate $(\mathrm{CMeC})$ at elevated temperature $\left(150^{\circ} \mathrm{C}\right)$. The $\mathrm{CMeC}$ had a degree of substitution (DS) of 0.17 after $3 \mathrm{~h}$ at $150{ }^{\circ} \mathrm{C}$. The original cellulose fibers had a very poor alkaline solubility, whereas the product with a DS of 0.17 exhibited a good alkaline solubility. In this process, dimethyl-urea degraded to methylamine and methylisocyanate to react with the hydroxyl groups of cellulose. The heat-driven reaction was significantly catalyzed by $\mathrm{ZnCl}_{2}$. Figure 4 illustrates the proposed mechanism for $\mathrm{CMeC}$ synthesis.

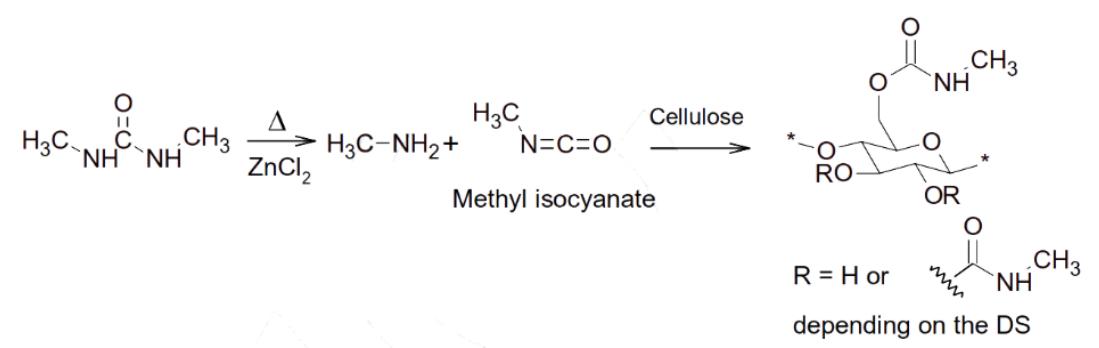

Figure 4. The proposed reaction mechanism for $\mathrm{CMeC}$ synthesis. Reprinted from reference [79] with permission.

Liu et al. [66] prepared a series of $\mathrm{FeCl}_{3} \cdot 6 \mathrm{H}_{2} \mathrm{O}$-based catalytic DESs with ethylene glycol, glycerol, malonic acid, L-alanine, L-serine, xylitol, pentaerythritol, and glycine as HBDs for transformation of cellulose to gluconic acid where the ferric chloride behaved as the catalyst. Most of the DESs had low viscosities, low melting points, and high conductivities. The high conductivities of the prepared DESs compared to other DESs and ILs are important for their electrochemical applications. Among the DESs, the $\left(\mathrm{FeCl}_{3} \cdot 6 \mathrm{H}_{2} \mathrm{O}\right.$ :ethylene glycol) DES showed the best performance, with $100 \%$ cellulose conversion and $53 \%$ gluconic acid yield in $1 \mathrm{~h}$ at $120^{\circ} \mathrm{C}$. The interesting point was that gluconic acid could self-precipitate, and the process of product separation could be skipped. Therefore, the employed method had the advantage of integrating solvent and catalyst as well as reaction and separation. Figure 5 illustrates the experimental procedure to obtain gluconic acid from glucose or cellulose. 


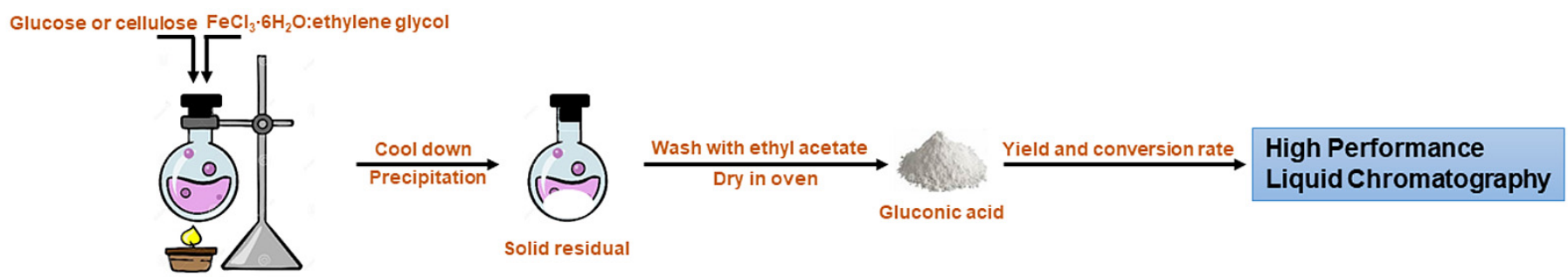

Figure 5. The experimental procedure to obtain gluconic acid from glucose or cellulose.

Recently, Yang et al. [82] fabricated cellulose nanocrystals (CNCs) from bleached eucalyptus kraft pulp (BEKP) using a $\mathrm{FeCl}_{3}$-catalyzed DES with a composition of (ChCl:oxalic acid $\cdot 2 \mathrm{H}_{2} \mathrm{O}: \mathrm{FeCl}_{3} \cdot 6 \mathrm{H}_{2} \mathrm{O}$ ) in a 1:4.43:0.1 molar ratio. This composition had the best swelling ability and strongest hydrolysis activity. Based on the cellulose content in BEKP, more than $90 \%$ CNC yield was obtained by a one-step DES treatment where the reaction took $6 \mathrm{~h}$ at $80{ }^{\circ} \mathrm{C}$. Under these conditions, glucose and xylose were also obtained. They found that the resultant $\mathrm{CNC}$ s had higher thermal stability than the traditional $\mathrm{H}_{2} \mathrm{SO}_{4}$-hydrolyzed ones.

\subsection{Processes Catalyzed by Brønsted Acid-Type DESs}

The Brønsted acidic DESs involve chemicals with an acidic character that can protonate other compounds for further reactions. The Brønsted acidity of DESs is mainly provided by their organic acid constituents. Therefore, a direct proportionality between the acidity of the HBD and that of the Brønsted acid-type DES is expected [112]. The common organic acids used to prepare Brønsted acid-type DESs include $p$-TSA [85], oxalic acid [69], malonic acid [69], citric acid [70], formic acid [73], glycolic acid [73], lactic acid [72], acetic acid [73], levulinic acid [72] and propionic acid [100], which are ordered from the strongest $(p-$ TSA) to the weakest (propionic acid) [113-119]. The DESs involving stronger Brønsted acids can fractionate the biomass more efficiently and consequently have higher catalytic capability [112]. DESs containing amides [69,76,77] and alcohols [76,98] can also perform as Brønsted acidic catalysts, which are inherently less acidic than those composed of organic acids. For example, Kumar et al. [120] found that the organic acid-based DESs could remove lignin and hemicellulose from biomass more efficiently than those DESs based on alcohols or amides. Moreover, the DESs with higher acidic characters were found to be more effective in lignin removal and glucan recovery [121]. However, the effect of the HBAs on the acidity of the liquids should not be ignored. For example, it has been found that the ammonium salts have major roles on the H-bond basicity of DESs [122]. Moreover, it was suggested that as the alkyl side chain of HBD or HBA in a specific DES increases, the solvent is less able to donate protons [122]. In another study on (ChCl:ethylene glycol) $\mathrm{DES}$, it was found that as the ratio of $\mathrm{ChCl}$ to ethylene glycol increases, the acidity of the liquid decreases which is due to the relatively more basic character of chloride compared to ethylene glycol [123]. Furthermore, it has been indicated that the higher number of H-bondforming groups (such as hydroxyl or amide groups) in a DES enhances the fractionation of the lignocellulosic biomass [124,125]. By the catalytic function of Brønsted acidic DESs, the biomass can be upgraded to biodiesel $[64,74,85-87,95]$, biofuel $[73,92,104]$, biocrude $[6,7]$, hydroxymethylfurfural (HMF) [69,70,75,89,90,94,101], furfural [71,88,94,97,109] and other value-added chemicals $[8,12,65,76,77,93,94,99,103,109]$ such as organic acids [12,94] and glucose and xylose $[93,109]$. The Brønsted acidic DESs can also be used in esterification of free fatty acids (FFAs) to glycerides [91,102] and delignification of biomass [72,96,100,105-108,110].

\subsubsection{Biodiesel/Biofuel Production by Brønsted Acid-Type DESs}

Biodiesel as a promising energy source is an alternative to fossil fuel and is produced from biological sources [126]. Biodiesel is biodegradable and non-toxic with negligible emission profiles [126]. In biodiesel production, the nature of the catalysts is critical in transesterification reactions and biomass transformation [127]. DESs have become a great target of attention for their capability as catalysts in biodiesel production [47]. For 
example, Hayyan et al. [85] produced internationally standard biodiesel from low-grade crude palm oil (LGCPO) in a two-stage process where a phosphonium-based DES made of $p$-TSA and allyl tri-phenyl phosphonium bromide (ATPPB) in a 1:3 molar ratio was used in the first stage as the catalyst. Different amounts of the DES $(0.25$ to $3.5 \% \mathrm{wt} / \mathrm{wt}$ of the DES to methanol) were used to decrease the level of FFA to an acceptable level for transesterification reaction in the second stage. The results showed that under optimum conditions, i.e., $1 \mathrm{wt} \% \mathrm{DES}, 10: 1 \mathrm{molar}$ ratio of methanol to LGCPO at $60^{\circ} \mathrm{C}$ for $30 \mathrm{~min}$, the DES had a high catalytic activity in the esterification of the LGCPO to reduce FFA from $9.3 \%$ to $<2 \%$. After the second stage and purification of biodiesel, the product yield was $89.84 \%$ with $0.06 \%$ FFA. Figure 6 displays the proposed flowchart to obtain glycerol and biodiesel from LGCPO.

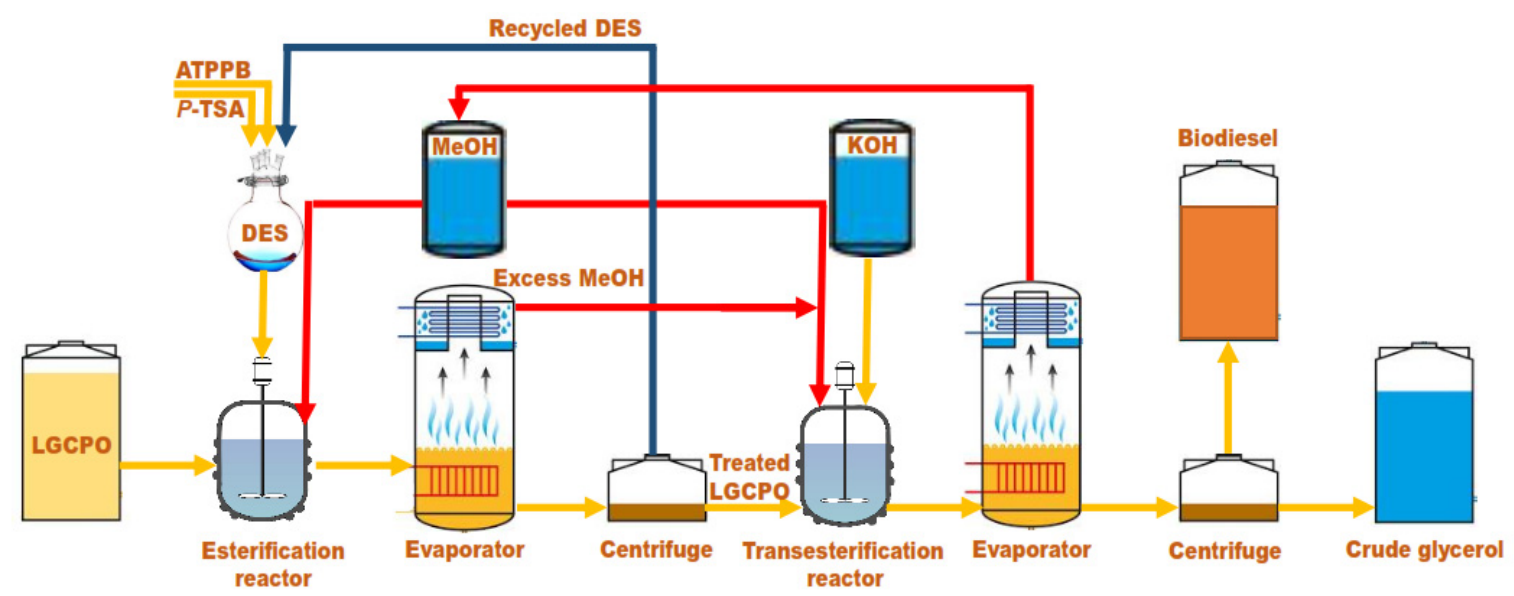

Figure 6. The flowchart to obtain glycerol and biodiesel from low-grade crude palm oil (LGCPO).

The same research group employed an ammonium-based DES composed of $p$-TSA and $\mathrm{N}, \mathrm{N}$-di-ethyl ethanol ammonium chloride (DEAC) in 1:3 molar ratio for biodiesel production from LGCPO via a pretreatment esterification stage [86]. With the optimum conditions of $0.75 \%$ (wt/wt) DES to LGCPO, 8:1 molar ratio of methanol to LGCPO, a reaction temperature of $60^{\circ} \mathrm{C}$ for $30 \mathrm{~min}$, the FFA content decreased from $9.5 \%$ in LGCPO to $<1 \%$. One year later, Hayyan et al. [87] used (ChCl:3p-TSA) DES for the conversion of FFAs in acidic crude palm oil (ACPO) to fatty acid methyl esters (FAME). With $0.75 \%$ $(w t / w t)$ DES to ACPO, 10:1 molar ratio of methanol to oil, at $60{ }^{\circ} \mathrm{C}$ and for $30 \mathrm{~min}$, the FFA reduced from $9 \%$ in ACPO to $<1 \%$. After the alkaline transesterification, the FAME content reached $96 \%$. Figure 7 displays the proposed process flowchart for biodiesel production from ACPO. 


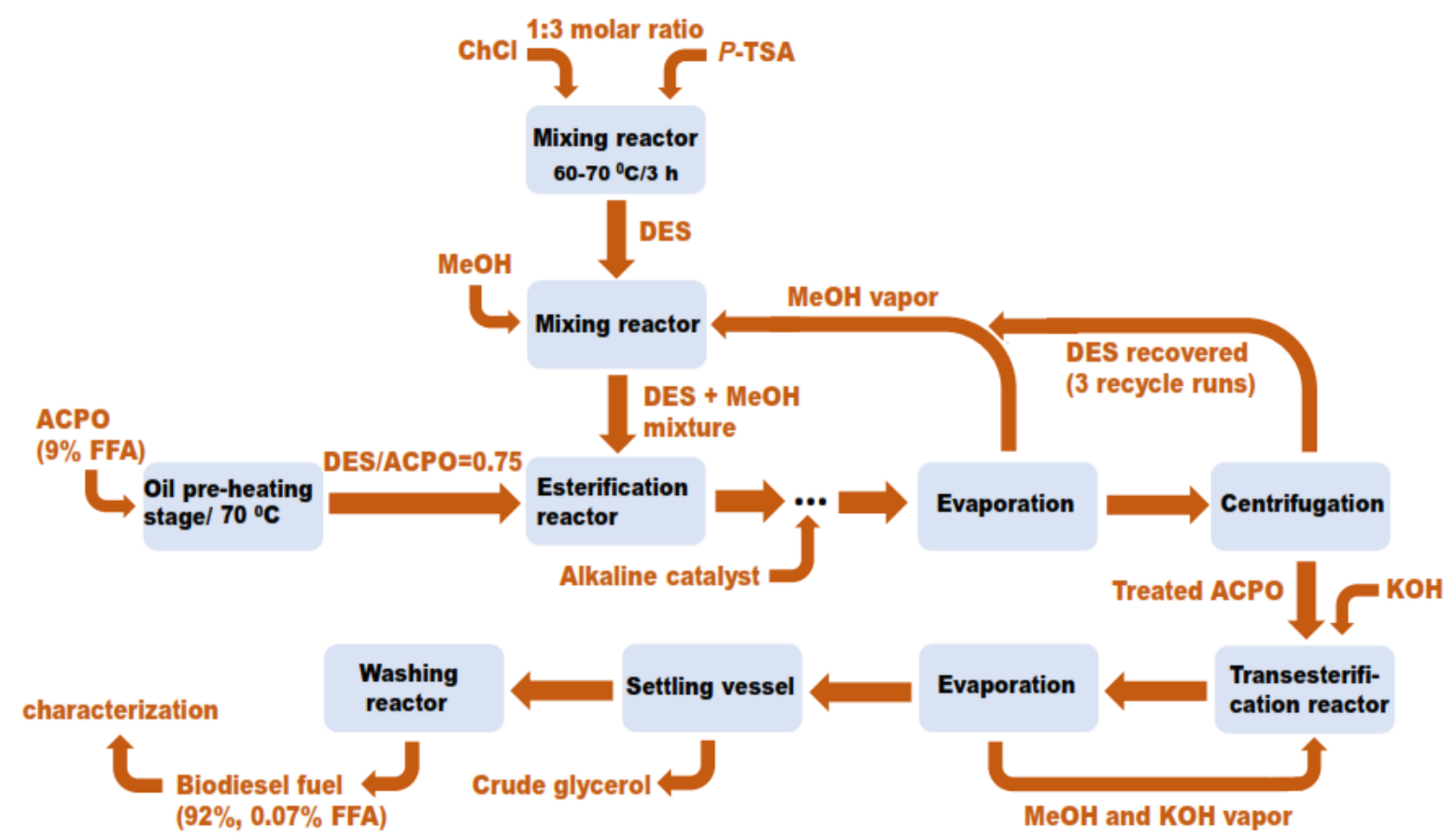

Figure 7. The flowchart for production of biodiesel from acidic crude palm oil (ACPO).

Alhassan et al. [64] used the biomass-derived Pongamia pinnata seed oil and (ChCl:4pTSA) DES to produce biodiesel in a single step. The DES was used with and without silica gel support, So-DES and Un-DES, as heterogeneous and homogeneous catalysts, respectively (Table 1). The DESs were characterized via their functional groups by Fourier transmission infrared (FTIR) spectroscopy to assess the active groups. The major functional groups characterized in the DESs were aromatic, carboxylic as well as amine and alkyl halides, with the spectra that were all characteristics of their constituents, meaning the behavior of the DESs is largely the function of their constituents. Additionally, the pore size and volume of the heterogeneous DES (So-DES) calcined at $623 \mathrm{~K}$ were investigated by scanning electron microscopy (SEM). The SEM images revealed the fragmentation of the silica granules clusters, suggesting a reduction in the particle size and increase in the surface area. This was accompanied by an enlarging of the interlayer spacing within So-DES that led to a decreased level of acidic sites on the surface of the catalyst that limited the reaction sites. Furthermore, the acidity of the catalysts was explored using ion exchange titrimetric method. It was found that the acidity of So-DES $\left(4.92 \pm 0.42 \mathrm{mmol} \mathrm{H}^{+} / \mathrm{g}\right)$ was slightly higher than that of Un-DES $\left(4.43 \pm 0.71 \mathrm{mmol} \mathrm{H}^{+} / \mathrm{g}\right)$. The acidities were attributed to the carboxylic acid and amine groups. Unfortunately, the authors did not characterize the recovered heterogeneous catalysts after the reactions.

With So-DES as heterogeneous catalyst and methanol as the solvent, at $353 \mathrm{~K}$ and 4.5 MPa for $4 \mathrm{~h}$ and with $5 \%(\mathrm{wt} / \mathrm{v})$ catalyst, the biodiesel conversion reached $89.3 \%$. However, with a dual role of catalyst and solvent, Un-DES reduced the reaction time and improved the phase homogeneity. With Un-DES, the biodiesel conversion reached $97.53 \%$. The optimum reaction conditions were $1 \%(\mathrm{wt} / \mathrm{v})$ catalyst at $343 \mathrm{~K}$ for $2 \mathrm{~h}$. Both catalysts were thermally stable during the esterification process. Yu et al. [95] alkylated isobutane and isobutene to obtain high-octane alkylate gasoline. They used a novel catalytic DES composed of tri-fluoro methane sulphonic acid (TfOH) and taurine in 3:1 molar ratio, dissolved in polyethylene glycol (PEG)-200 (43\% wt/wt DES to PEG-200) to yield a very stable mixture with suitable acidity. Using this mixture and under optimum conditions, i.e., at $80{ }^{\circ} \mathrm{C}$ for $1 \mathrm{~h}$ with the stirring rate of $800 \mathrm{rpm}$, the isobutene conversion was as high as $82.59 \%$ with $\mathrm{C}_{8}$ selectivity reaching $85.54 \%$. Shen at al. [74] produced biodiesel from yellow horn seed biomass by a one-pot method using a DES made of $p$-TSA and tetra-butyl ammonium bromide (TBAB) in 1:2 molar ratio, performing as solvent and 
catalyst. Keeping the temperature at $72{ }^{\circ} \mathrm{C}$ for $40 \mathrm{~min}$, and with a $27: 1$ mass ratio of liquid to seed and $11 \mathrm{wt} \%$ of DES, $90.33 \%$ and $96.53 \%$ of oil extraction and FAME conversion were achieved, respectively.

The compound 5-ethoxymethyl furfural (5-EMF) is a liquid biofuel with high energy density close to that of diesel, gasoline and ethanol and is considered as a potential additive to diesel and gasoline [128]. In one study [92], the one-pot synthesis of 5-EMF was carried out for the first time under microwave heating from fructose at mild conditions using a variety of DESs. Among all the DESs, $\mathrm{ChCl}$ :oxalic acid had the best catalytic results with $92 \%$ conversion of fructose to yield $74 \% 5-\mathrm{EMF}$ at $343 \mathrm{~K}$ for $3 \mathrm{~h}$. The conversion was related to the acidic nature of DES. During the process, the parallel reaction of fructose with the in situ-generated ethanol and water along with the reaction of ethanol and EMF led to formation of ethyl levulinate, which is also regarded as a fuel additive.

\subsubsection{Biocrude Production by Brønsted Acid-Type DESs}

Biocrude is obtained from lignocellulosic biomass under high temperature (200-350 ${ }^{\circ} \mathrm{C}$ ) and pressure (5-15 MPa) and is usually treated to recover bio-oil. Further upgrading results in production of biofuels with high energy density. The higher heating values (HHVs) of some biocrudes are close to those of petroleum-based crudes [129,130]. There are a few studies where acidic DESs have been used as catalysts to yield biocrude via hydrothermal liquefaction (HTL) processes. For example, Alhassan et al. [6] used de-oiled Jatropha curcas cake to produce biocrude. The biomass was catalyzed by four DESs, namely $(\mathrm{ChCl}: 4 \mathrm{KOH}),(\mathrm{ChCl}: 4 p-\mathrm{TsOH}),(\mathrm{ChCl}: 3 g l y c e r o l)$ and $\left(\mathrm{ChCl}: 3 \mathrm{FeCl}_{3}\right)$ through a HTL process. The produced biocrude had HHVs from around 21.15 to $24.30 \mathrm{MJ} / \mathrm{kg}$. The yield of the biocrude was the most, $43.53 \mathrm{wt} \%$, using (ChCl:4KOH) DES, followed by 38.31 wt $\%$ with $\mathrm{ChCl}: 4 p$-TsOH DES. However, the only Lewis acidic DES, $\mathrm{ChCl}: 3 \mathrm{FeCl}_{3}$, had the least biocrude yield (30.80 wt\%). The HBDs-containing DESs preferentially favored producing aromatic oils through condensation and hydrolysis of lipids. Unlike the other DESs used in this study, with $\mathrm{ChCl}$ :3glycerol DES, the long reaction time decreased the biocrude oil yield. One year later, Alhassan et al. [7] performed a comparative study on liquefaction of Jatropha curcas seed biomass using $\mathrm{Na}_{2} \mathrm{CO}_{3}$ catalyst and co-liquefaction of the same biomass with glycerol (30 wt \%) using ChCl:p-TSA DES to obtain biocrude. The results showed the higher biocrude yield via liquefaction process (32.87 wt \%) than that of co-liquefaction process $(8.99 \mathrm{wt} \%)$. However, the $\mathrm{HHV}$ of the biocrude from co-liquefaction process $(\sim 31.73 \mathrm{MJ} / \mathrm{kg})$ was higher than that of the biocrude from liquefaction process $(\sim 28.80 \mathrm{MJ} / \mathrm{kg})$. The reaction temperature was found to be the most important factor on the bio-oil yield, followed by biomass loading and catalyst type. Figure 8 displays the proposed diagram for hydrothermal liquefaction and co-liquefaction of Jatropha curcas seed biomass.

\subsubsection{5-HMF Production by Brønsted Acid-Type DESs}

The platform compound 5-hydroxymethylfurfural (5-HMF) produced from lignocellulosic biomass is an intermediate for synthesis of downstream furan derivatives, levulinic acid and many other valuable chemicals (Figure 9) [131,132]. 


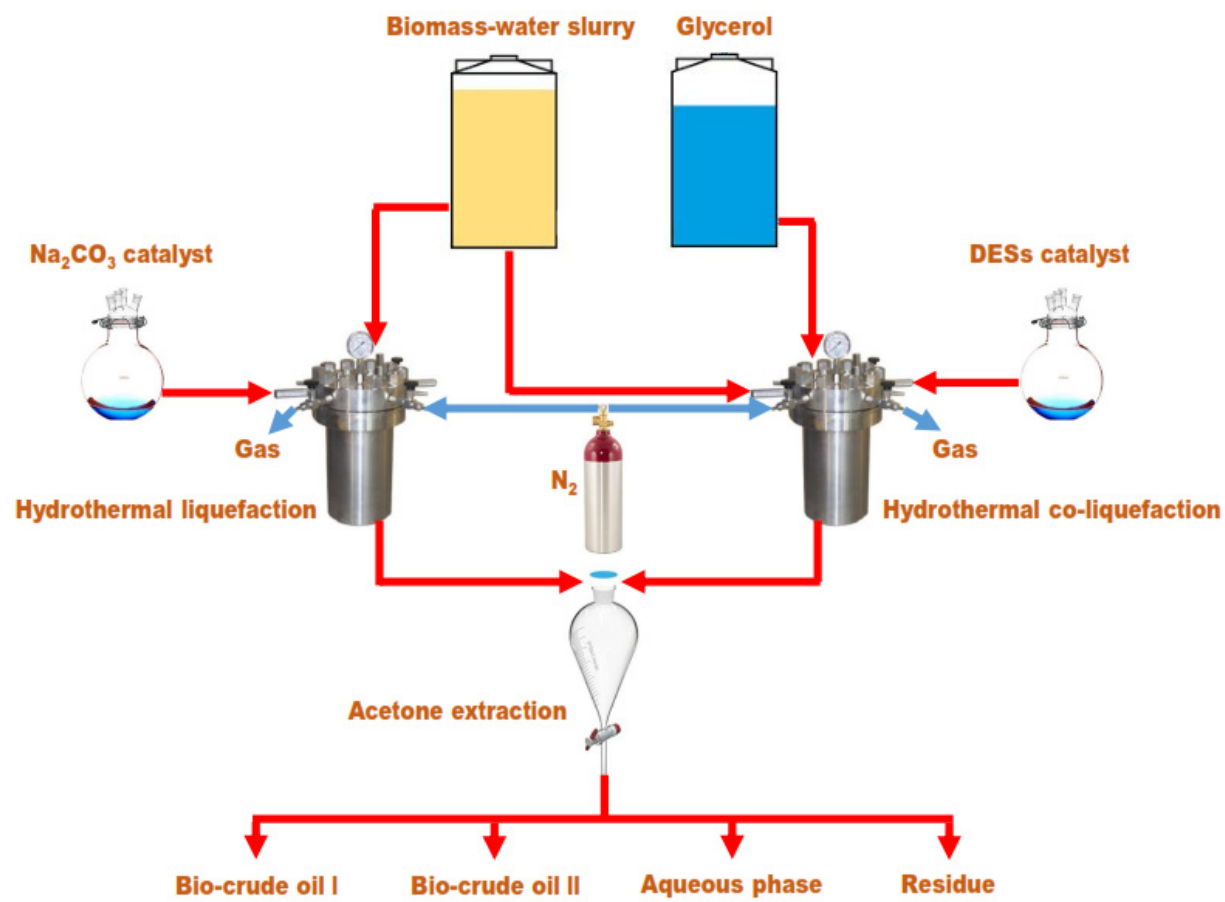

Figure 8. The schematic diagram for hydrothermal (co)liquefaction of Jatropha curcas seed biomass.

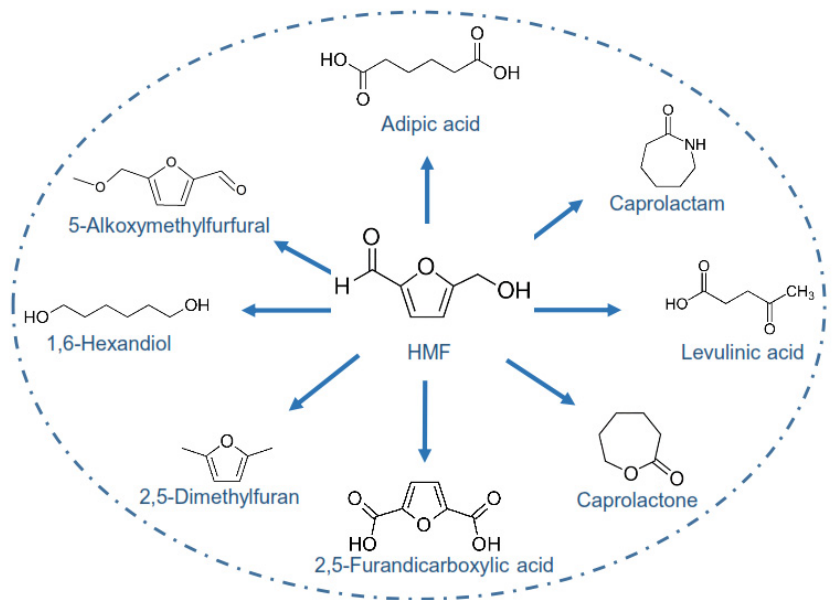

Figure 9. Some possible derivatives from 5-HMF.

The acidic DES-catalyzed dehydration of carbohydrates to obtain 5-HMF has been reported $[69,70,75,89,90,94,101]$. Hu et al. [69] synthesized several catalytic DESs, namely ChCl:2urea, ChCl: $2 \mathrm{ZnCl}_{2}, \mathrm{ChCl}: 2 \mathrm{CrCl}_{3} \cdot 6 \mathrm{H}_{2} \mathrm{O}, \mathrm{ChCl}$ :malonic acid, ChCl:oxalic acid $\cdot 2 \mathrm{H}_{2} \mathrm{O}$, $2 \mathrm{ChCl}$ :citric acid $\cdot \mathrm{H}_{2} \mathrm{O}$ and $2 \mathrm{ChCl}$ :citric acid to convert fructose to 5- $\mathrm{HMF}$ in a 5:1 molar ratio of DES to fructose. As shown schematically in Figure 10, the obtained intermediate 5-HMF was then used to produce liquid fuel and value-added chemicals. 


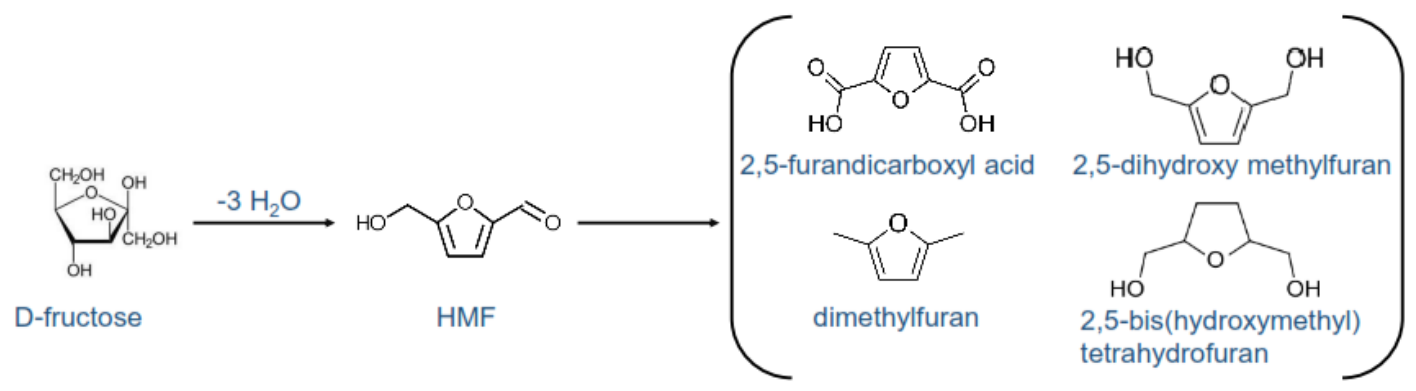

Figure 10. The obtained 5-HMF as an intermediate from carbohydrates to produce biofuel and value-added chemicals [69].

The results showed that the Brønsted acidic DESs, particularly $\mathrm{ChCl}$ :malonic acid, $\mathrm{ChCl}$ :oxalic acid $\cdot 2 \mathrm{H}_{2} \mathrm{O}$ and $2 \mathrm{ChCl}$ :citric acid $\cdot \mathrm{H}_{2} \mathrm{O}$, were effective to convert fructose to 5 HMF (91-100\%). Conversely, the Lewis acidic DESs, $\mathrm{ChCl}: 2 \mathrm{ZnCl}_{2}$ and $\mathrm{ChCl}: 2 \mathrm{CrCl}_{3} \cdot 6 \mathrm{H}_{2} \mathrm{O}$, were inefficient in producing 5 -HMF. More than $90 \%$ of the fructose conversion was obtained at $80^{\circ} \mathrm{C}$ after $1 \mathrm{~h}$. One year later, Hu et al. [70] employed inulin as the biomass material to transform it to 5-HMF in one pot reaction using $\mathrm{ChCl}$ :oxalic acid and $2 \mathrm{ChCl}$ :citric acid DESs as both catalysts and solvents. At $80{ }^{\circ} \mathrm{C}$ and for $2 \mathrm{~h}$, the yield of 5-HMF and the selectivity were $64 \%$ and $57 \%$, and $64 \%$ and $65 \%$ with ChCl:oxalic acid and $2 \mathrm{ChCl}$ :citric acid DESs, respectively. Assanosi et. al. [89] used an acidic DES, ChCl:p-TSA, to dehydrate fructose in order to obtain 5-HMF. The DES had the dual role of HBD and catalyst. The highest 5-HMF yield, $90.7 \%$, was obtained at $80{ }^{\circ} \mathrm{C}$ in $1 \mathrm{~h}$ with the feed ratio of $2.5 \%$. In another study, sunflower stalk was used as the biomass with high cellulose content to obtain some value-added chemicals including 5-HMF [94]. The process involved employing a catalytic DES composed of DEACl and oxalic acid in 3:2 molar ratio in a microwave reactor to convert the cellulosic biomass. The conversion yield of the cellulose was examined at different temperatures and reactions times. At the optimum conditions, i.e., $170{ }^{\circ} \mathrm{C}$ within $5 \mathrm{~min}$, the maximum carbon conversion was achieved as $38.4 \%$, with the highest yield relating to levulinic acid followed by formic acid, furfural and 5-HMF. Ruan et al. [101] used a bifunctional DES composed of imidazole (Im) and benzene sulfonic acid (BSA) in 1:1.5 molar ratio to perform as both catalyst and solvent for dehydration of fructose to 5-HMF. The acidity of the DES could be tuned by changing the molar ratio of the HBA and HBD. With $10 \%$ DES and after a short reaction time of $3 \mathrm{~min}$ at $100{ }^{\circ} \mathrm{C}$, the 5 -HMF yield reached $90.1 \%$. They found that the solvent effect of DES was due to the formation of H-bonds between $\mathrm{Im}^{+}$and/or BSA ${ }^{-}$components and fructose.

Very recently, Zhang et al. [75] decomposed glucose to 5-HMF in microreactors using several DESs. They added different inorganic salts to the system and observed that for the catalytic mechanism, synergistic effects were best revealed between $\mathrm{CrCl}_{3}$ and $\mathrm{ChCl}$ of (ChCl:2ethylene glycol) DES. At $150{ }^{\circ} \mathrm{C}$ and in less than $4 \mathrm{~min}$, the 5-HMF yield reached $42 \%$. As shown in Figure 11, the dehydration of fructose to 5-HMF was obtained under the influence of the $[\mathrm{ChCl}]^{+}\left[\mathrm{CrCl}_{4}\right]^{-}$complex. 


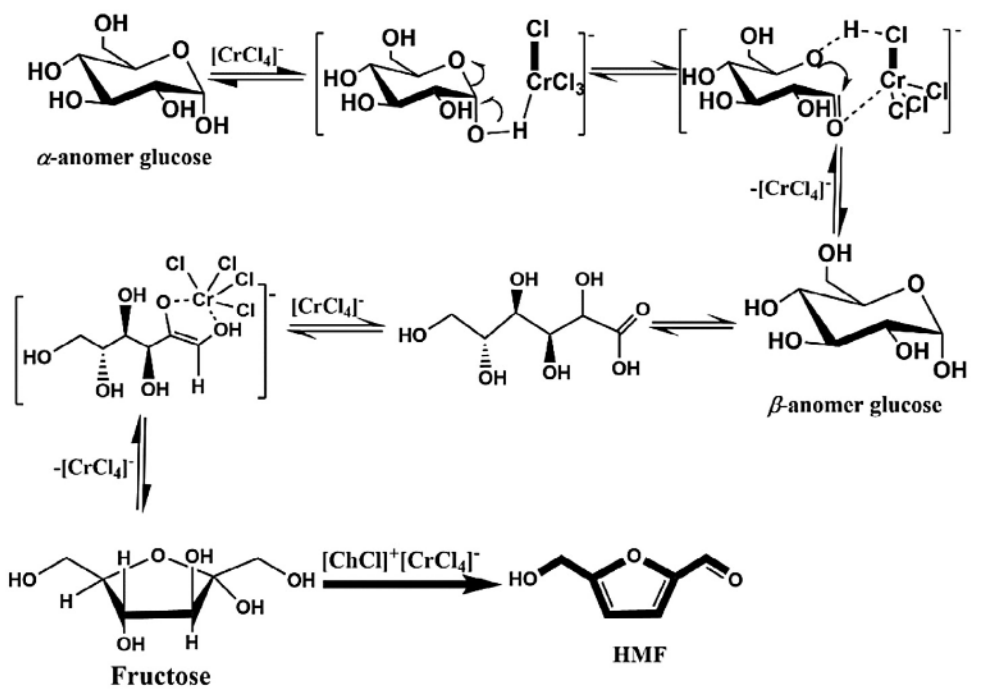

Figure 11. The proposed mechanism pathway for dehydration of glucose to 5-HMF. Reprinted from reference [75] with permission.

\subsubsection{Furfural Production by Brønsted Acid-Type DESs}

Furfural is a versatile and important bio-based compound derived from lignocellulosic biomass and is used to produce some key platform chemicals [88]. The US department of energy has identified furfural as one of the top value-added compounds with a large world market [133]. For furfural production, industrial processes using mineral acids for pretreatment of biomass or using high-pressure steam for stripping furfural suffered from several drawbacks, most importantly the low efficiency and high energy consumption [88]. The recently investigated approach to produce furfural employed catalysts $[134,135]$ among them are DESs $[71,88,97]$. Zhang et al. [71] converted xylan and xylose into furfural in a reactor co-catalyzed by trivalent metal chloride $\left(\mathrm{AlCl}_{3} \cdot 6 \mathrm{H}_{2} \mathrm{O}\right.$ and $\left.\mathrm{FeCl}_{3} \cdot 6 \mathrm{H}_{2} \mathrm{O}\right)$ and $\mathrm{ChCl}$ :2citric acid $\cdot \mathrm{H}_{2} \mathrm{O}$ DES in both monophasic (only DES) and biphasic (DES + methyl isobutyl ketone (MIBK)) processes. The highest furfural yields with monophasic process from xylose and xylan were $59.3 \%\left(140{ }^{\circ} \mathrm{C}, 15 \mathrm{~min}\right)$ and $54.2 \%\left(140{ }^{\circ} \mathrm{C}, 25 \mathrm{~min}\right)$, respectively. In the biphasic system, the highest furfural yields from xylose and xylan were $73.1 \%$ $\left(140{ }^{\circ} \mathrm{C}, 25 \mathrm{~min}\right)$ and $68.6 \%\left(140{ }^{\circ} \mathrm{C}, 35 \mathrm{~min}\right)$, respectively. In both processes, $\mathrm{AlCl}_{3} \cdot 6 \mathrm{H}_{2} \mathrm{O}$ was the selected metal chloride for optimum conditions. Recently, Morais et al. [97] tried two acidic DESs, ChCl:malic acid and ChCl:glycolic acid in different molar ratios, to act as both catalyst and solvent for the conversion of xylan to furfural. In their study, the effects of water and $\gamma$-valerolactone (GVL) contents, microwave heating and solid to liquid ratio (S/L) were considered. The highest furfural yield, $75 \%$, was achieved with $\mathrm{ChCl}$ :3malic acid DES containing $5 \mathrm{wt} \%$ water at $150^{\circ} \mathrm{C}$ for $2.5 \mathrm{~min}$, with S/L of 0.05 and the GVL weight ratio of 2:1. Figure 12 represents the proposed flowchart for recovery of the produced furfural from xylan. 


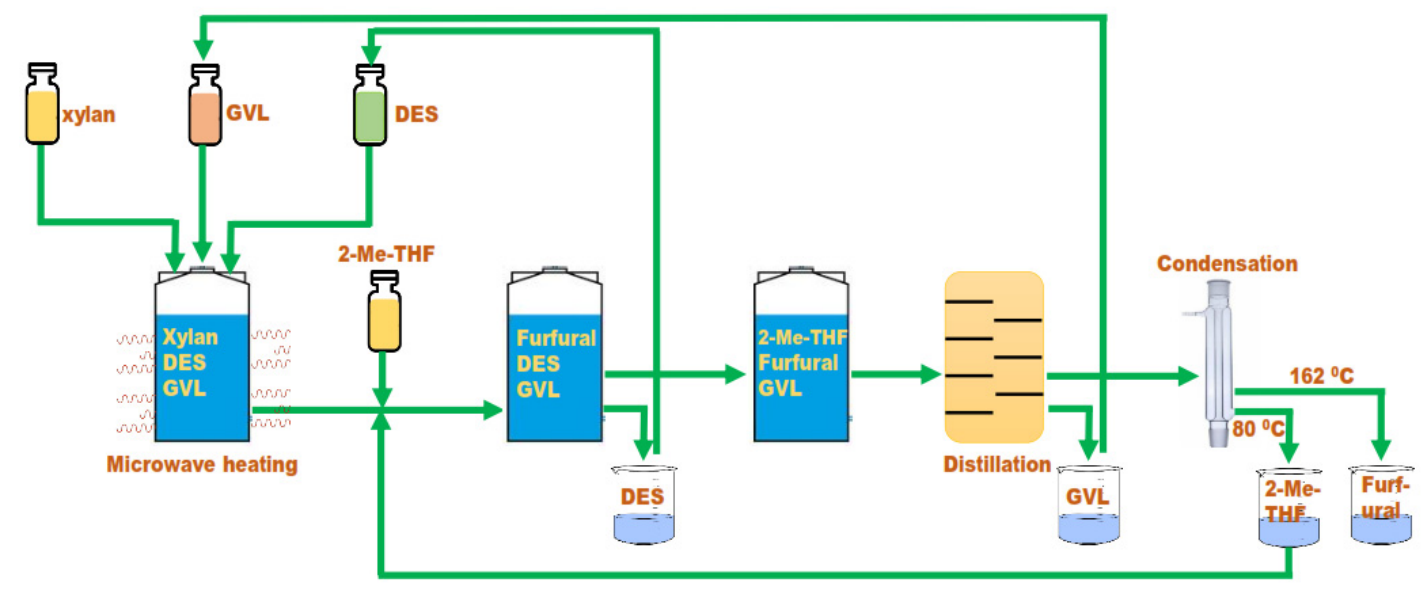

Figure 12. The proposed diagram for recovery of the produced furfural from xylan.

\subsubsection{Delignification of Biomass by Brønsted Acid-Type DESs}

Lignin is the most abundant renewable biomass constituent on earth [72]. Researchers have been searching for effective techniques to remove lignin from biomass and to valorize it. Because lignin is an integral part of the lignocellulosic biomass cell walls, the separation of lignin in high quantity and with good purity is not readily possible, unless the native biomass is remarkably changed [14,136-139]. The recent applications of DESs in biorefinery processes have provided novel insights towards their potential application in biomass treatment for lignin removal and its valorization [29]. Moreover, DESs have emerging applications as catalysts in the delignification processes $[72,73,96,100,105-108,110]$. AlvarezVasco et al. [72] extracted low molecular weight lignin from hardwood (poplar) and softwood (D. fir) biomass using four catalytic DESs, namely ChCl:acetic acid, ChCl:lactic acid, ChCl:levulinic acid and ChCl:glycerol. They discovered that these acidic DESs could catalytically cleave ether linkages in the biomass to facilitate lignin removal. At $145{ }^{\circ} \mathrm{C}$, all the used DESs could extract more than $70 \%$ of polar lignin. However, the highest lignin extraction, 78.5\%, was achieved with (ChCl:lactic acid) DES. Regarding the D. fir biomass, the maximum extraction yield of lignin was obtained at $145^{\circ} \mathrm{C}$ with all the employed DESs. The highest lignin yield, $58.2 \%$, was observed when using (ChCl:lactic acid) DES. For both hardwood and softwood feedstock, the further increase in temperature to $180^{\circ} \mathrm{C}$ led to a decrease in lignin extraction.

The delignification mechanism and the catalytic cleavage of $\beta-\mathrm{O}-4$ ether bond present in biomass were studied on the lignin model 2-phenoxy-1-phenylethanol (PPE) compound with acidic DESs [100]. To this purpose, three DESs, namely 2propionic acid:urea, $\mathrm{ChCl}$ :10lactic acid and ChCl:p-TSA were used. The acidity of each DES affected the $\beta$ $O-4$ ether bond. Among the DESs, 2propionic acid:urea DES was unable to delignify the biomass model due to its incapacity to cleave the ether bond. On the other hand, $\mathrm{ChCl}$ :10lactic acid DES could cleave the ether bond in PPE, but an unwanted esterification reaction between PPE and lactic acid along with oligomerization of lactic acid occurred. The other DES, ChCl:p-TSA, had the highest performance for PPE cleavage with 57.7\% phenol content at $120{ }^{\circ} \mathrm{C}$. However, the high acidity of $p$-TSA resulted in the condensation of produced species. It was found that the presence of water reduced the DES ability to cleave the ether bond. In addition, the identification of chlorinated and brominated species of PPE (PPE-Cl/Br) before the ether bond cleavage when using ChCl:p-TSA and ChBr:p-TSA DESs revealed the role of halide ion of the DESs in the cleavage of ether bond (Figure 13). 


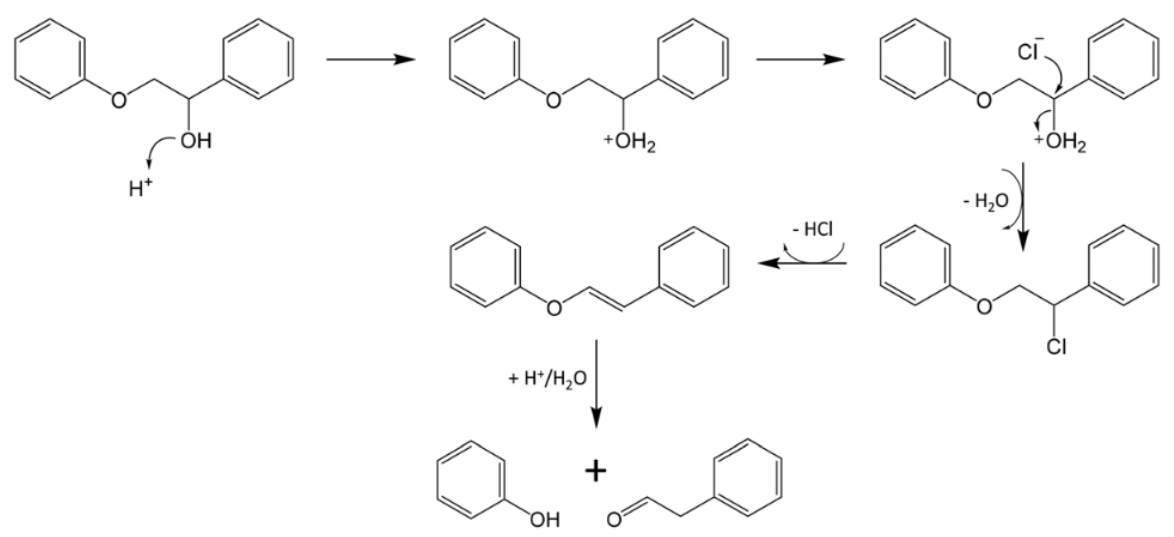

Figure 13. The proposed mechanism for the production of the chlorinated species. The same mechanism can be considered for the brominated species. Reprinted from reference [100] with permission.

Wang et al. [105] used enzymatic mild acidolysis lignin (EMAL) which has been derived from Eucalyptus tree and $\beta-O-4$ lignin model compounds to study the structural variant of lignin fractions after pretreatment with an acidic DES, ChCl:2lactic acid, at different temperatures and reaction times. They found that in both realistic and model lignin, the $\beta-\mathrm{O}-4$ linkages were cleaved under the influence of the catalytic action of the DES, leading to a decrease in the molecular weight and increase in the hydroxyl groups. They also found that repolymerization of the lignin fragments after depolymerization of lignin may account for the low efficiency of the monomeric products of lignin. Figure 14 illustrates the proposed flowchart for lignin treatment with DES.

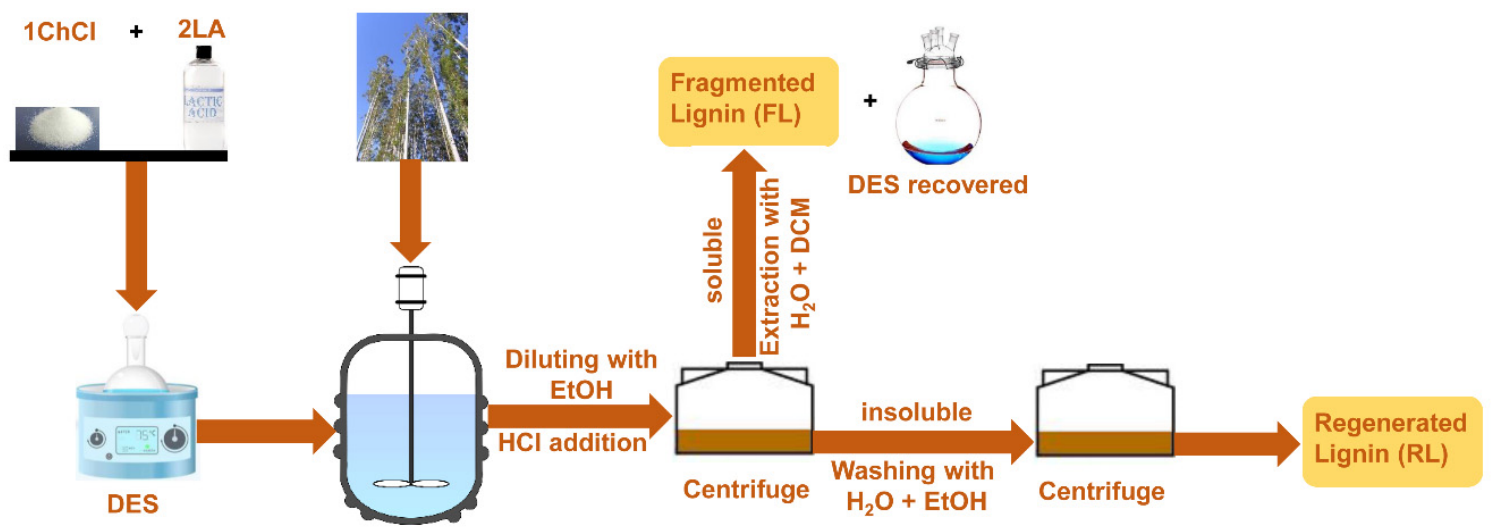

Figure 14. The flowchart for lignin treatment with DES.

Shen et al. [106] investigated the effect of (ChCl:10lactic acid) DES pretreatment on the structural properties of double enzymatic lignin (DEL) derived from Eucalyptus tree at temperatures in the range of 60 to $140{ }^{\circ} \mathrm{C}$ after $6 \mathrm{~h}$. The yields of the major depolymerized products (the monomeric species), i.e., vanillin, acetovanillone, guaiacol and guaiacylacetone, were the highest at $140{ }^{\circ} \mathrm{C}$. The nuclear magnetic resonance (NMR) results showed that cleavage of $\beta-O-4$ bonds is dominant during the pretreatment with the DES along with increased phenolic hydroxyl. Moreover, at elevated pretreatment temperatures, acylation or dehydration of aliphatic hydroxyl groups and partial recondensation of lignin occurred. Remarkably, they found that the DES pretreatment led to a homogeneous lignin morphology as well as facilitation of lignin nanoparticle formation that enables the fabrication of nanomaterials based on lignin. It is worth mentioning that the yields of the degraded monomers were relatively low, implying that the DES pretreatment did not lead to serious degradation of lignin. Tian et al. [110] tried three acidic DESs, namely $\mathrm{ChCl}$ :2formic acid, $\mathrm{ChCl}$ :2acetic acid and $\mathrm{ChCl}$ :lactic acid, to extract lignin and enhance cellulose reactivity 
from poplar wood shavings at mild conditions after a first step of liquid hot water extraction. The cellulose pulps resulted from DESs pretreatment had comparable chemical reactivity to bleached Kraft pulp. The two features of the used DESs, i.e., their acidity and ionic nature, were found to be influential in lignin selectivity sand deconstruction of cellulose. The increase in cellulose reactivity was ascribed to the dissociation of $\mathrm{H}$ bonds by the acidic DESs. Among the three DESs, $\mathrm{ChCl}$ :2acetic acid DES had the highest compromise between selective extraction of lignin (76.5\%) and cellulose accessibility (85.4\%) for material conversion.

\subsubsection{Other Value-Added Chemicals' Production by Brønsted Acid-Type DESs}

The applications of Brønsted acid-type DESs are not restricted to the above-mentioned materials, and there are a number of other processes where DESs function as catalysts $[8,12,65,76,77,93,94,99,103,109]$. Wang et al. [8] used three acidic DESs, namely ChCl:oxalic acid $2 \mathrm{H}_{2} \mathrm{O}, \mathrm{ChCl}$ :malonic acid and $\mathrm{ChCl}$ :citric acid $\cdot \mathrm{H}_{2} \mathrm{O}$ to catalyze epoxidation of soybean oil under solvent-free conditions. With $\left(\mathrm{ChCl}\right.$ :oxalic acid $\left.2 \mathrm{H}_{2} \mathrm{O}\right) \mathrm{DES}$ at $50{ }^{\circ} \mathrm{C}$ for $8 \mathrm{~h}$, the conversion of the double bond (\%), epoxidized soybean oil (ESBO) yield (\%) and selectivity (\%) were 88.80, 83.19 and 93.68, respectively. With $\mathrm{ChCl:malonic}$ acid DES at $50{ }^{\circ} \mathrm{C}$ for $10 \mathrm{~h}$, the conversion of the double bond (\%), ESBO yield (\%) and selectivity (\%) were 85.36, 77.57 and 90.87, respectively. With $\mathrm{ChCl}$ :citric acid $\cdot \mathrm{H}_{2} \mathrm{O} \mathrm{DES}$ at $50{ }^{\circ} \mathrm{C}$ for $8 \mathrm{~h}$, the conversion of the double bond (\%), ESBO yield (\%) and selectivity (\%) were 74.53, 62.25 and 83.52, respectively. Clearly, it is seen that at the optimum condition, ChCl:oxalic acid. $2 \mathrm{H}_{2} \mathrm{O}$ DES has the best catalytic performance among the DESs used. Figure 15 depicts the flowchart for the production of ESBO.

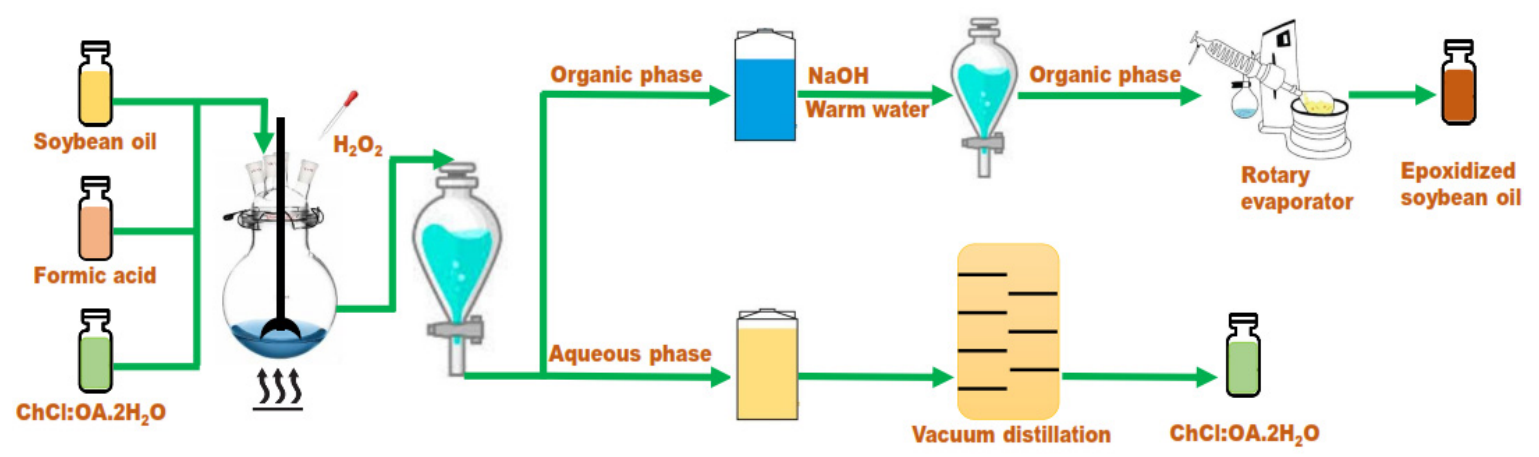

Figure 15. The flowchart for production of epoxidized soybean oil (ESBO).

Bodachivskyi et al. [93] used a combination of 1-butyl-3-methylimidazolium chloride ionic liquid and $\mathrm{ChCl}$ :oxalic acid DES as an excellent solvent-catalyst system to convert cellulose and native biomass into saccharides with low molecular weights such as glucose, cellobiose, cellotriose, cellotetraose and xylose. At the optimized conditions $\left(120{ }^{\circ} \mathrm{C}, 6 \mathrm{~h}\right)$, the yield and selectivity were as high as $85 \%$ and $98 \%$, respectively. The acid-catalyzed conversion of cellulose was mainly into glucan oligomer chunks from which glucose was obtained. The transformation to glucose was improved by modifying the DESs acidities via addition of Lewis acids or water. Ni et al. [12] oxidize furfural to produce maleic acid and fumaric acid in $\mathrm{ChCl}$ :oxalic acid green DES as both solvent and catalyst. At $50{ }^{\circ} \mathrm{C}$ and with hydrogen peroxide as the oxidizer, furfural could be converted up to $100 \%$ to yield maleic acid and fumaric acid as high as $95.7 \%$. Here, the DES was diluted with water to reduce the viscosity. The molar ratio of the DES constituents was also changed to find the optimum composition. It was found that with $4 \mathrm{ChCl}$ :oxalic acid DES, the yields of fumaric acid and fumaric acid + maleic acid were $26 \%$ and $46.9 \%$, respectively. In addition, the yield of maleic acid reached $25.3 \%$ at 2:1 molar ratio. However, because the viscosity of $4 \mathrm{ChCl}$ :oxalic acid DES was high, the 3:1 molar ratio was chosen for further studies. Figure 16 shows the reaction scheme for transformation of furfural into the acids under optimized conditions. 


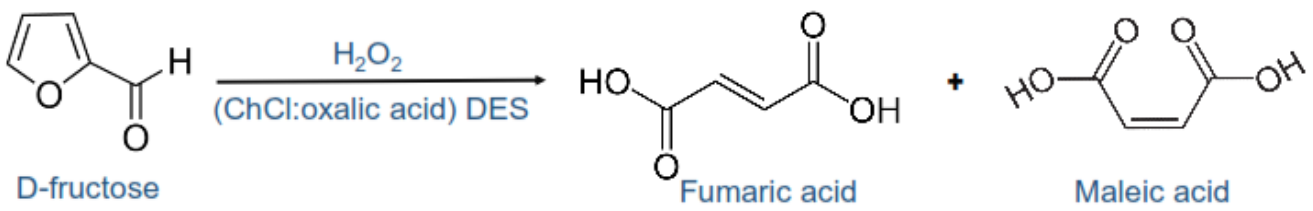

Figure 16. The reaction scheme for conversion of furfural to fumaric acid and maleic acid [12].

Zhang et al. [99] performed a one-step conversion of $\alpha$-pinene to $\alpha$-terpineol, where the process was catalyzed by a ternary homogeneous natural DES (NADES) prepared from oxalic acid dihydrate and betaine. Regarding the catalytic activity, selectivity and recyclability, the 1:2.7 molar ratio of the (betaine:oxalic acid $2 \mathrm{H}_{2} \mathrm{O}$ ) NADES was found a promising catalyst for hydration of $\alpha$-pinene. The conversion of $\alpha$-pinene and selectivity for $\alpha$-terpineol were $91.91 \%$ and $34.63 \%$, respectively. Additionally, the hydration products were as high as $36.84 \%$. Water in the system acted as both a critical constituent of the NADES and the dispersing agent. As the water content increased, the $\alpha$-pinene conversion gradually decreased while the $\alpha$-terpineol selectivity increased. The optimum water content was $0.30 \mathrm{~mol}$ percent to lead to the best $\alpha$-terpineol yield. Sert et al. [65] converted levulinic acid to ethyl levulinate with ethanol in the presence of catalytic DESs via esterification. To proceed, carboxylic acids were selected as HBDs to synthesize six ChCl-based DESs: $\mathrm{ChCl}$ 2acetic acid, $\mathrm{ChCl}$ :malonic acid, $\mathrm{ChCl}$ :oxalic acid, $\mathrm{ChCl}$ :citric acid, $(\mathrm{ChCl}$ 2formic acid and $3 \mathrm{ChCl}: 7 p$-TSA. Different operating conditions were tried in a batch reactor. Among all the factors influencing the conversion yield, the acidity of the DESs followed by temperature were the most important ones. It was found that the most catalytically active DES was (ChCl:p-TSA). The highest levulinic acid conversion and ethyl levulinate selectivity were obtained to be, respectively, $99.8 \%$ and $99.9 \%$ at $353 \mathrm{~K}$ for $1 \mathrm{~h}$ with $5 \mathrm{wt} \%$ of the DES. Bodachivskyi et al. [109] catalytically valorized low-value biomass (corn husk, corncob, softwood, U. lactuca, P. cruentum) into value-added chemicals in a DES composed of $\mathrm{ChCl}$ and oxalic acid (ChCl:oxalic acid). They found that the acidic DES enhanced the transformation of branched glucans, fructans and xylans into glucose, fructose, xylose, HMF and furfural with yields up to $68 \%, 60 \%, 73 \%, 14 \%$ and $72 \%$, respectively. The optimum conditions for conversions were found as $200 \mathrm{mg}$ of the biomass, $4.0 \mathrm{~g}$ of the DES, $8.0 \mathrm{~mL}$ of solvent-extractant (ethyl acetate, MIBK, anisole, 1,2-dimethoxy-benzene) at $100{ }^{\circ} \mathrm{C}$ for $2 \mathrm{~h}$.

Williamson et al. [91] reduced oleic acid as FFA in low-grade oil through an esterification reaction with glycerol to obtain mono- and di-glycerides. In this process, a DES prepared from ATPPB and $p$-TSA in 1:3 molar ratio was used as a catalyst. The effect of parameters such as temperature and DES concentration on the efficiency of esterification were studied. The lowest activation energy, $54.64 \mathrm{~kJ} / \mathrm{mol}$, was obtained with $5 \mathrm{wt} \%$ of the DES. At $150{ }^{\circ} \mathrm{C}$ for $30 \mathrm{~min}$, with $5 \mathrm{wt} \%$ catalyst and at a $6: 1$ molar ratio of glycerol to oleic acid, $95 \%$ of oleic acid was converted. Under this condition, $85 \%$ of mono- and di-glycerides were produced.

\section{Recyclability of Catalytic DESs}

In the chemical industry, recycling technology is an important stage towards sustainability [86]. Recyclability usually involves separation, purification and reusing a solvent or catalyst in successive steps, namely recovering step, refining step and recycling (reusing) step [47]. The whole process greatly affects the solvent or catalyst's utilization in industrial processes from economic and environmental aspects. In general, the more recyclable a solvent or catalyst, the better it is. In most cases, the chemical efficiency is directly correlated with the recyclability. The recyclability of the applied catalytic DESs have been evaluated in several studies. For example, Song et al. [77] performed a reusability experiment of $\mathrm{ChCl}$ :2urea DES in methanolysis of polycarbonate under the optimum reaction conditions. They found that the DES could be reused five times with no significant reduction in polycarbonate conversion, indicating the good reusability of the DES. In the process of conversion 
of cellulose to gluconic acid, Liu et al. [66] reported no loss of the catalytic activity of $2 \mathrm{FeCl}_{3} \cdot 6 \mathrm{H}_{2} \mathrm{O}$ :ethylene glycol DES, which was due to the self-precipitation of gluconic acid from the reaction system. Liu et al. [81] used the catalytic DES (1,3-dimethylurea: $\mathrm{ZnCl}_{2}$ ) in 4:1 molar ratio to convert polyethylene terephthalate (PET) to bis(hydroxyalkyl) terephthalate (BHET). As is shown in Figure 17, the catalyst worked efficiently after being recycled five times.

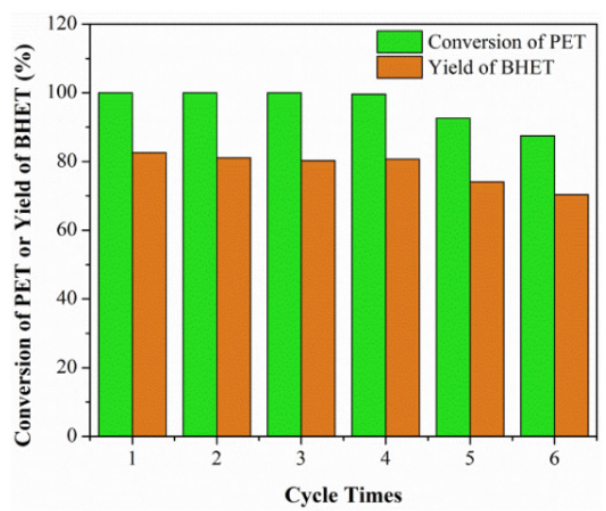

Figure 17. Recycling efficiency of the employed catalyst. Reprinted from reference [81] with permission.

The recyclability of (ChCl:oxalic acid $\left.\cdot 2 \mathrm{H}_{2} \mathrm{O}\right) \mathrm{DES}$, used as a catalyst in the conversion of inulin to 5-HMF, was investigated [70]. The results indicated that activity of the recycled DES was very high even after utilization six times. The same DES was investigated for its reusability as a catalyst in the epoxidation of soybean oil [8]. It was found that $\mathrm{ChCl}$ :oxalic acid $2 \mathrm{H}_{2} \mathrm{O}$ DES had good catalytic activity, with $90 \%$ selectivity after five recycle runs under optimum conditions. Hayyan et al. [85] studied the recyclability of (ATPPB:3pTSA) DES employed as a catalyst in biodiesel production from LGCPO. They found that the DES had a high conversion yield in the first three recycle runs, while the efficiency reduced in the fourth recycle run. They suggested that the main advantage of using the DES was its reusability andthat using $p$-TSA alone as a catalyst would not facilitate acid recycling, because of the loss of the acid in the product. The same research group performed the recyclability experiment of the employed catalytic DES, ChCl:3p-TSA, in the process of FFA conversion to FAME [87]. The results revealed that first and second runs of recycling had high efficiencies, while for the third run, a slight reduction in the conversion yield was observed. Therefore, a lengthened reaction time was suggested to have the same yield as the first two runs. However, the successful reusability of the DES was dependent on the efficiency of the catalyst separation by centrifugation. Alhassan et al. [64] examined the recycling of $\mathrm{ChCl} 44$-TSA catalytic DESs (So-DES and Un-DES). A highspeed centrifuge was used to regenerate the catalysts. Then, the biodiesel production was performed, employing the recycled DESs under optimum conditions. For Un-DES, marginal reduction in the catalytic activity was observed for the first four runs. For SoDES, after eight successive experiments, catalytic activity reduced after, which the catalyst became deactivated. Deactivation was proposed to be due to the decrease in the density of the acidic sites.

The catalytic (ATPPB:3p-TSA) DES was used to reduce the oleic acid in low-grade oil via esterification process [91]. The results showed that for five repeated recycle runs, the catalytic efficiency of the DES did not change significantly, implying that the DES catalyst regained its high catalytic activity even after several usages. Compared to the study by Hayyan et al. [85] where the same DES catalyst was employed, the DES catalyst in this study worked more efficiently (five recycle runs compared to three recycle runs). However, it should be noted that in the present study, more catalyst was used (5.0 wt $\%)$ than $1.0 \mathrm{wt} \%$ used by Hayyan et al. Yu et al. [95] used (taurine:3TfOH) DES dissolved in PEG-200 to alkylate isobutane and isobutene for production of gasoline. After the reaction was completed, the alkylate oil was simply separated from taurine: $3 \mathrm{TfOH}+$ 
PEG-200 catalytic system via decantation. They found that after eight times of using the catalyst, the isobutane and isobutene conversion rates and octane selectivity did not drop significantly. Additionally, compared to pure $\mathrm{TfOH}$, taurine:3TfOH or TfOH/PEG-200, the taurine:3TfOH + PEG-200 catalytic system worked remarkably better in terms of reusability and octane selectivity.

In order to investigate the reusability of (TBAB:2p-TSA) catalyst in a process of biodiesel production from yellow horn seed biomass, Shen et al. [74] examined the FAMEs conversion yield and oil extraction yield in several runs. They found that the oil extraction yield was nearly unchanged and the conversion yield of FAME reached $80 \%$ after four recycle runs. They did not recommend more than four runs of recycling because glycerol, as the by-product of the process, hindered the transesterification reaction. Zhang et al. [75] tested the reusability of the ( $\mathrm{ChCl}$ :2ethylene glycol) $+\mathrm{CrCl}_{3}$ catalytic system employed for 5 -HMF production. After the decomposition of glucose, ethyl acetate was employed as an extraction solvent to separate 5-HMF, levulinic acid and formic acid from the reaction mixture. Because of the very low solubility of (ChCl:2ethylene glycol) and $\mathrm{CrCl}_{3}$ in ethyl acetate, 5-HMF was readily separated from the mixture. The remaining liquid was heated to remove the residual solvent from the catalytic system. The catalytic system could be used up to four times, with $38 \%$ yield of 5-HMF. Therefore, the catalytic system could be successfully recycled for decomposition of glucose to 5-HMF for four times.

\section{Limitations of DESs}

DESs are superior over other common organic solvents, due to their features mentioned above, for sustainability. However, despite the many remarkable properties of DESs, acting either as catalysts and/or reaction media in biomass transformations, there are a number of limitations restricting their use. For instance, the biomass conversions are usually carried out at high temperatures. Some DESs may decompose or undergo side reactions under those conditions. For example, there are studies reporting the decomposition of the DES constituents and formation of unwanted chemicals at high temperatures [31,32]. Moreover, it has been reported that some types of DESs composed of $\mathrm{ChCl}$ and carboxylic acids underwent esterification reactions as a consequence of interactions between hydroxyl groups of the salt and the acids [33]. For similar reasons, the suitability of DESs with high melting points, such as type I DESs, which are composed of an organic salt and a non-hydrated metal salt, for industrial applications is highly limited $[2,140]$.

The other concern about the applicability of DESs in biomass conversions is their recyclability. As given in Table 1, the recyclability of DESs of both types of Brønsted acids and Lewis acids is hardly greater than 6 times, after which their efficiencies drop significantly. Difficulties in purification of DESs after several recycling processes has created serious constraints towards scaling up. There are therefore only a few studies reporting scaling-up processes containing DESs [141,142]. The usually high viscosities of DESs along with high melting points of some of them would result in reduced mass transfer during the pretreatment process, hampering their applications and recyclability $[143,144]$. However, as a well-practiced approach, water addition would circumvent the high viscosities of DESs $[26,145]$. This practice may have also a positive influence on the efficiency of the process [143].

Finally, it has been argued that the impurities and minerals present in feedstock can change the physicochemical properties of the DESs negatively and impact their catalytic properties [146].

\section{Conclusions and Future Prospects}

Based on the principles of green chemistry, solvents used in chemical industries should have some criteria such as low toxicity and safety with less negative impacts on the environment. In search for a solvent with these criteria, ILs were initially introduced as fulfilling several of the green chemistry-based principles. However, there are a number of drawbacks when using many ILs, such as toxicity, low biodegradability and high 
cost, among others. To tackle these shortcomings, a new type of greener solvents, DESs, was introduced as favorable replacements to ILs with several superiorities such as less toxicity, lower cost, ease of preparation and high thermal stability. In addition, green chemistry strongly recommends the use of catalytic reagents, in particular the ones with high selectivity. Green chemistry also emphasizes the renewability of feedstock and raw material used in chemical industries. On the other hand, the depletion of fossil fuel reserves, ever-increasing requests for energy, and the consequent environmental impact have shifted the global policy from the fossil fuels to renewable energy resources such as lignocellulosic biomass. All these facts led us to conclude the necessity of using catalytic DESs in conversion and upgrading the renewable lignocellulosic biomass towards valueadded chemicals.

Therefore, in this article, we reviewed the latest advancements in using DESs as catalysts (and in many cases, DESs had a dual role of solvent and catalyst) in upgrading biomass towards value-added compounds. Based on the constituents, the catalytic DESs were divided into two groups: Lewis acid-type catalysts containing chlorides of transition metals and Brønsted acid-type DESs containing HBDs such as organic acids, alcohols and amides. It was shown that the valorization of biomass using these catalytic DESs resulted in various products such as biodiesel, biofuel, biocrude, HMF, furfural, organic acids, glucose and xylose (Figures 18 and 19).

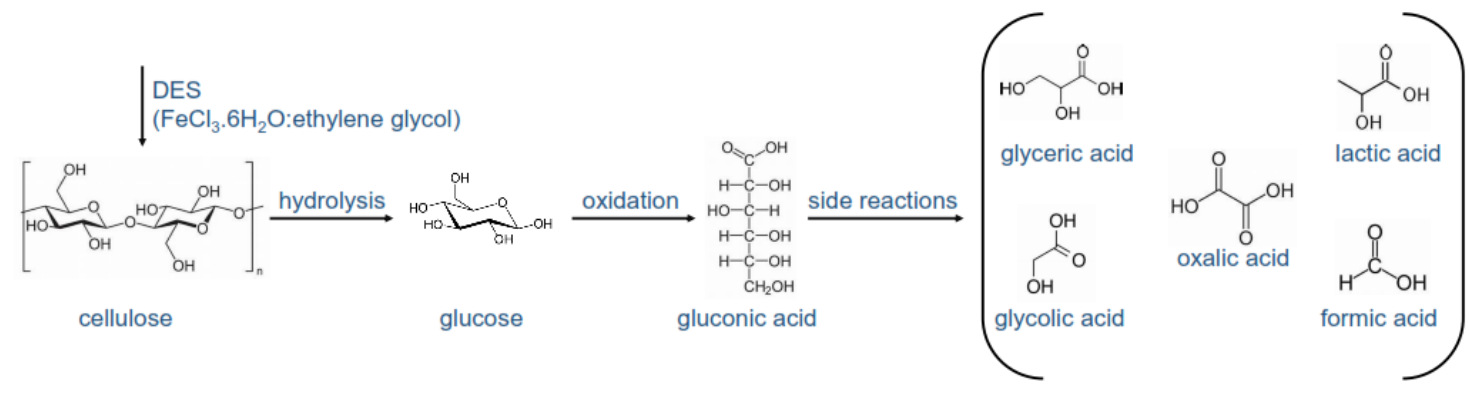

Figure 18. The typical reaction pathway for conversion of cellulosic biomass into value-added chemicals using Lewis acid-type catalytic DESs.

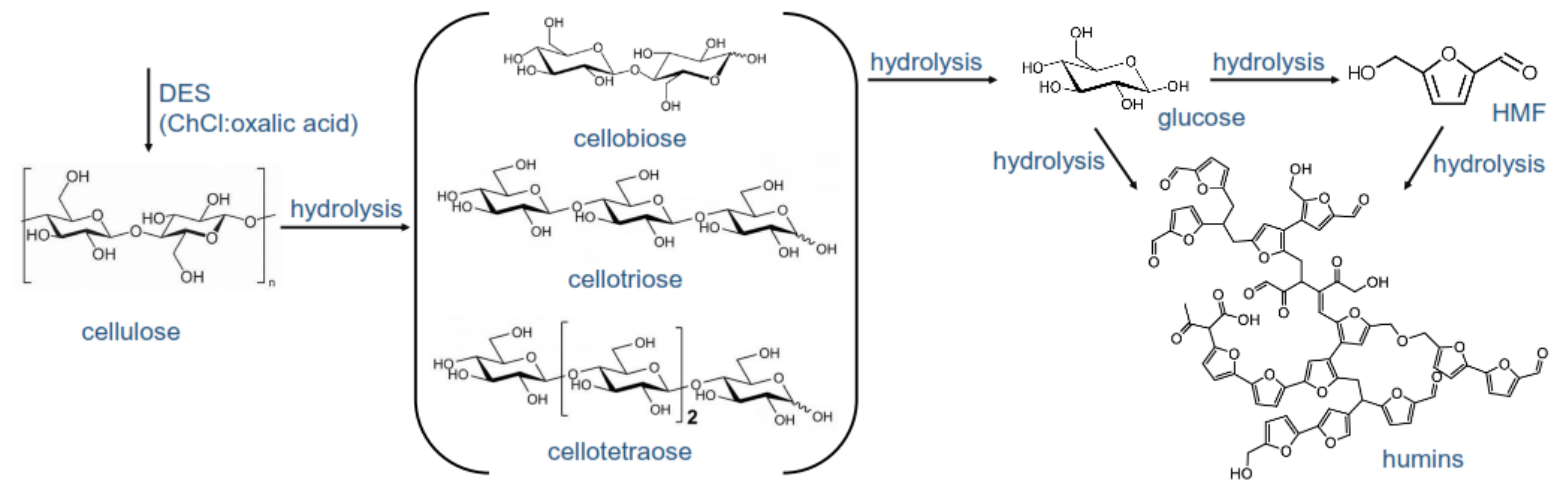

Figure 19. The typical reaction pathway for conversion of cellulosic biomass into value-added chemicals using Brønsted acid-type catalytic DESs.

However, despite all this encouraging progress, the number of DESs used in valorization of feedstock is limited, and therefore prospective opportunities are vast in this field. There are several gaps in our knowledge of catalytic applications of DESs in the valorization of feedstock, which are described in the following.

(1) One gap is on the performance of the catalytic DESs in heterogeneous mode. To the best of the authors' knowledge, there is only one research article [64] utilizing the catalytic DESs in heterogeneous mode. Even in that study, the heterogeneous catalyst 
was not characterized after use in the catalytic reactions. This clearly shows that the studies of heterogeneous catalytic DESs have been largely ignored in the field, a field that is now being investigated in our lab.

(2) There is no investigation of chemical integrity of DES-based heterogeneous catalysts. In particular, it is very important to do multielement, non-destructive elemental analysis of the heterogeneous catalysts as a function of cycles of use to develop a mechanistic understanding of the change to catalytic action and therefore optimizing the heterogeneous DES-based catalysts. This should ideally be done on the surface and under the surface of the catalysts.

(3) There is a lack of information about approaches to develop DES-based heterogeneous catalysts. The homogeneous catalytic DESs with favorable features or the newly synthesized ones can be modified to be used as heterogeneous catalysts. In this way, the costly process of separation of the homogeneous catalyst from the reaction media, which is usually the evaporation of the mixture, is replaced by a simple centrifugal process. Another direction that is ongoing in our lab is to make these catalysts with proper physical properties that would respond to external fields to move them out of the reaction mixture using external fields. An important feature of properly functioning heterogeneous catalysts is the temperature at which the chemicals are adsorbed/desorbed on/from the catalyst. Here, designing heterogeneous catalytic DESs functioning at moderate temperatures seems demanding. In addition, designing heterogeneous catalytic DESs accommodating adequate amounts of effective functional groups facilitates various biomass transformations in a one-pot approach. Other desired properties of the heterogeneous catalytic DESs pursued in our lab include the low production cost and durability. Multiple catalytic reusability with no significant reduction of the functionality would make the designed catalysts more sustainable and cost-effective.

(4) There is a lack of computational insights about catalytic properties of DESs. Computational studies are needed to obtain an in-depth molecular-level insight into the chemical mechanisms through which DESs affect the biomass. This would help to synthesize more efficient DESs with favorable properties suitable for a specific type of application. For example, molecular dynamics (MD) simulations can be used to simulate the realistic systems where catalytic DESs operate on the biomass components. In this way, the desired properties of the system can be investigated and predicted, and the functionality of the DES or its concentration towards favorable conditions can be optimized. Furthermore, the functionality of various DESs can be tested at very low price. More importantly, MD simulations allow applying high temperatures and pressures in the desired system with no risk to assess the behavior of the biomass and the DES. This makes it much easier to inspect the effects of high temperatures and pressures on the multicomponent systems involved and use this information to select experimental conditions. Moreover, the effect of mixing different cosolvents on the physicochemical properties and final products of the system can be explored as well. The static quantum chemical calculations such as ab initio and density functional theory methods can provide complementary valuable information on, for instance, the most reactive sites of the biomass components towards various catalytic DESs. Acquiring ideas on the strength of the intermolecular interactions between the DES, and biomass is another important information obtainable from such calculations which, in turn, gives a measure of how reactive the two moieties are. This knowledge helps to select the most efficient catalytic DESs for a specific biomass component.

Funding: This research was partially funded by The Natural Sciences and Engineering Research Council of Canada (NSERC).

Conflicts of Interest: The authors state that they have no conflict of interest. 


\section{References}

1. Abbott, A.P.; Capper, G.; Davies, D.L.; Rasheed, R.K.; Tambyrajah, V. Novel solvent properties of choline chloride/urea mixtures. Chem. Commun. 2003, 70-71. [CrossRef] [PubMed]

2. Smith, E.L.; Abbott, A.P.; Ryder, K.S. Deep eutectic solvents (DESs) and their applications. Chem. Rev. 2014, 114, 11060-11082. [CrossRef] [PubMed]

3. Zhang, Q.; Vigier, K.D.O.; Franc, S.R.; Jerome, F. Deep eutectic solvents: Syntheses, properties and applications. Chem. Soc. Rev. 2012, 41, 7108-7146. [CrossRef] [PubMed]

4. Xu, G.C.; Ding, J.C.; Han, R.Z.; Dong, J.J.; Ni, Y. Enhancing cellulose accessibility of corn stover by deep eutectic solvent pretreatment for butanol fermentation. Bioresour. Technol. 2016, 2-3, 364-369. [CrossRef] [PubMed]

5. Procentese, A.; Raganati, F.; Olivieri, G.; Elena, M.; Rehmann, L.; Marzocchella, A. Low-energy biomass pretreatment with deep eutectic solvents for bio-butanol production. Bioresour. Technol. 2017, 243, 464-473. [CrossRef]

6. Alhassan, Y.; Kumar, N.; Bugaje, I.M. Hydrothermal liquefaction of de-oiled Jatropha curcas cake using deep eutectic solvents (DESs) as catalysts and co-solvents. Bioresour. Technol. 2016, 199, 375-381. [CrossRef]

7. Alhassan, Y.; Pali, H.S.; Kumar, N.; Bugaje, I.M. Co-liquefaction of whole Jatropha curcas seed and glycerol using deep eutectic solvents as catalysts. Energy 2017, 138, 48-59. [CrossRef]

8. Wang, J.; Liu, Y.; Zhou, Z.; Fu, Y.; Chang, J. Epoxidation of soybean oil catalyzed by deep eutectic solvents based on the choline chloride-carboxylic acid bifunctional catalytic system. Ind. Eng. Chem. Res. 2017, 56, 8224-8234. [CrossRef]

9. Jerome, F.; Vigier, K.D.O. Catalytic conversion of carbohydrates to furanic derivatives in the presence of choline chloride. Catalysts 2017, 7, 218. [CrossRef]

10. Unlu, A.E.; Arikaya, A.; Takac, S. Use of deep eutectic solvents as catalyst: A mini-review. Green Process. Synth. 2019, 8, 355-372. [CrossRef]

11. Körner, S.; Albert, J.; Held, C. Catalytic low-temperature dehydration of fructose to 5-hydroxymethylfurfural using acidic deep eutectic solvents and polyoxometalate catalysts. Front. Chem. 2019, 7, 661. [CrossRef] [PubMed]

12. Ni, Y.; Bi, Z.; Su, H.; Yan, L. Deep eutectic solvent (DES) as both solvent and catalyst for oxidation of furfural to maleic acid and fumaric acid. Green Chem. 2019, 21, 1075-1079. [CrossRef]

13. Bai, C.; Wei, Q.; Ren, X. Selective extraction of collagen peptides with high purity from cod skins by deep eutectic solvents. ACS Sustain. Chem. Eng. 2017, 5, 7220-7227. [CrossRef]

14. Chen, Z.; Bai, X.; Lusi, A.; Wan, C. High-solid lignocellulose processing enabled by natural deep eutectic solvent for lignin extraction and industrially relevant production of renewable chemicals. ACS Sustain. Chem. Eng. 2018, 6, 12205-12216. [CrossRef]

15. Cao, Q.; Li, J.; Xia, Y.; Li, W.; Luo, S.; Ma, C.; Liu, S. Green extraction of six phenolic compounds from rattan (calamoideae faberii) with deep eutectic solvent by homogenate-assisted vacuum-cavitation method. Molecules 2019, 24, 113. [CrossRef]

16. Garc, G.; Aparicio, S.; Ullah, R.; Atilhan, M. Deep eutectic solvents: Physicochemical properties and gas separation applications. Energy Fuels 2015, 29, 2616-2644. [CrossRef]

17. Tan, T.; Zhang, M.L.; Wan, Y.Q.; Qiu, H.D. Utilization of deep eutectic solvents as novel mobile phase additives for improving the separation of bioactive quaternary alkaloids. Talanta 2016, 149, 85-90. [CrossRef]

18. Florindo, C.; Lima, F.; Ribeiro, B.D.; Marrucho, I.M. Deep eutectic solvents: Overcoming 21st century challenges. Curr. Opin. Green Sustain. Chem. 2019, 18,31-36. [CrossRef]

19. Ghandi, K. A review of ionic liquids, their limits and applications. Green Sustain. Chem. 2014, 4, 44-53. [CrossRef]

20. Sas, O.G.; Fidalgo, R.; Domínguez, I.; Macedo, E.A.; González, B. Physical properties of the pure deep eutectic solvent, [ChCl]:[Lev] (1:2) DES, and its binary mixtures with alcohols. J. Chem. Eng. Data 2016, 61, 4191-4202. [CrossRef]

21. Harifi-Mood, A.R.; Buchner, R. Density, viscosity, and conductivity of choline chloride + ethylene glycol as a deep eutectic solvent and its binary mixtures with dimethyl sulfoxide. J. Mol. Liq. 2017, 225, 689-695. [CrossRef]

22. Kalhor, P.; Xu, J.; Ashraf, H.; Cao, B.; Yu, Z.W. Structural properties and hydrogen-bonding interactions in binary mixtures containing a deep-eutectic solvent and acetonitrile. J. Phys. Chem. B 2020, 124, 1229-1239. [CrossRef] [PubMed]

23. Meng, X.; Ballerat-busserolles, K.; Andanson, J. Impact of water on the melting temperature of urea+choline chloride deep eutectic solvent. New J. Chem. 2016, 40, 4492-4499. [CrossRef]

24. Zhekenov, T.; Toksanbayev, N.; Kazakbayeva, Z.; Shah, D. Formation of type III Deep Eutectic Solvents and effect of water on their intermolecular interactions. Fluid Phase Equilibria 2017, 441, 43-48. [CrossRef]

25. Hammond, O.S.; Bowron, D.T.; Edler, K.J. The effect of water upon deep eutectic solvent nanostructure: An unusual transition from ionic mixture to aqueous solution. Angew.Chem. Int. Ed. 2017, 56, 9782-9785. [CrossRef] [PubMed]

26. Kalhor, P.; Zheng, Y.Z.; Ashraf, H.; Cao, B.; Yu, Z.W. Influence of hydration on the structure and interactions of Ethaline deep-eutectic solvent: A spectroscopic and computational study. ChemPhysChem 2020, 21, 995-1005. [CrossRef]

27. Kalhor, P.; Li, Q.Z.; Zheng, Y.Z.; Yu, Z.W. Is the Fourier transform infrared free-OH band of t-butanol only from free OHs? case studies on the binary systems of the alcohol with $\mathrm{CCl}_{4}$ and $\mathrm{CHCl}_{3}$. J. Phys. Chem. A 2020, 124, 6177-6185. [CrossRef] [PubMed]

28. Kalhor, P.; $\mathrm{Yu}, \mathrm{Z}$.W. Structural and hydrogen-bonding properties of neat $\mathrm{t}-\mathrm{BuNH}_{2}$ and its binary mixtures with $\mathrm{CCl}_{4}, \mathrm{CHCl}_{3}$ and DMSO. J. Mol. Struct. 2020, 1215, 128257. [CrossRef]

29. Kalhor, P.; Ghandi, K. Deep eutectic solvents for pretreatment, extraction, and catalysis of biomass and food waste. Molecules 2019, 24, 4012. [CrossRef] 
30. Abbott, A.P.; Boothby, D.; Capper, G.; Davies, D.L.; Rasheed, R.K. Deep eutectic solvents formed between choline chloride and carboxylic acids: Versatile alternatives to ionic liquids. J. Am. Chem. Soc. 2004, 126, 9142-9147. [CrossRef]

31. Florindo, C.; Oliveira, F.S.; Rebelo, L.P.N.; Fernandes, A.M.; Marueho, I.M. Insights into the synthesis and properties of deep eutectic solvents based on cholinum chloride and carboxylic acid. ACS Sustain. Chem. Eng. 2014, 2, 2416-2425. [CrossRef]

32. Simeonov, S.P.; Afonso, C.A.M. Basicity and stability of urea deep eutectic solvents. RSC Adv. 2016, 6, 5485-5490. [CrossRef]

33. Kroon, M.C.; Binnemans, K. Degradation of deep-eutectic solvents based on choline chloride and carboxylic acids. ACS Sustain. Chem. Eng. 2019, 7, 11521-11528.

34. Ishida, N.; Miura, T.; Murakami, M. Hydrothermal liquefaction of model food waste biomolecules and ternary mixtures under isothermal and fast conditions. Chem. Commun. 2007, 6, 4381-4383. [CrossRef] [PubMed]

35. Tan, Y.; Chen, Y.; Mahimwalla, Z.; Johnson, M.B.; Sharma, T.; Brüning, R.; Ghandi, K. Novel synthesis of rutile titanium dioxide-Polypyrrole nano composites and their application in hydrogen generation. Synth. Met. 2014, 189, 77-85. [CrossRef]

36. Kannan, S.; Gariepy, Y.; Raghavan, G.S.V. Conventional hydrothermal carbonization of shrimp waste. Energy Fuels 2018, 32, 3532-3542. [CrossRef]

37. Chen, W.T.; Zhang, Y.; Zhang, J.; Schideman, L.; Yu, G.; Zhang, P.; Minarick, M. Co-liquefaction of swine manure and mixedculture algal biomass from a wastewater treatment system to produce bio-crude oil. Appl. Energy 2014, 128, 209-216. [CrossRef]

38. Ghandi, S.K.; Gordon, M.S. Ultra-fast electron capture by electrostericallystabilized gold nanoparticles. Nanoscale 2015, 7, 11545-11551. [CrossRef]

39. Wu, C.; Wang, Q.; Xiang, J.; Yu, M.; Chang, Q.; Gao, M.; Sonomoto, K. Enhanced productions and recoveries of ethanol and methane from food waste by a three-stage process. Energy Fuels 2015, 29, 6494-6500. [CrossRef]

40. Yu, X.; Yin, J.; Wang, K.; Shen, D.; Long, Y.; Chen, T. Enhancing food waste hydrolysis and the production rate of volatile fatty acids by prefermentation and hydrothermal pretreatments. Energy Fuels 2016, 30, 4002-4008. [CrossRef]

41. Déniel, M.; Haarlemmer, G.; Roubaud, A.; Weiss-Hortala, E.; Fages, J. Bio-oil production from food processing residues: Improving the bio-oil yield and quality by aqueous phase recycle in hydrothermal liquefaction of blackcurrant (Ribes nigrum L.) pomace. Energy Fuels 2016, 30, 4895-4904.

42. Dagle, V.L.; Smith, C.; Flake, M.; Albrecht, K.O.; Gray, M.J.; Ramasamy, K.K.; Dagle, R.A. Integrated process for the catalytic conversion of biomass-derived syngas into transportation fuels. Green Chem. 2016, 18, 1880-1891. [CrossRef]

43. Zhang, B.; Lin, Q.; Zhang, Q.; Wu, K.; Pu, W.; Yang, M.; Wu, Y. Catalytic hydrothermal liquefaction of Euglena sp. microalgae over zeolite catalysts for the production of bio-oil. RSC Adv. 2017, 7, 8944-8951. [CrossRef]

44. Posmanik, R.; Cantero, D.A.; Malkani, A.; Sills, D.L.; Tester, J.W. Biomass conversion to bio-oil using sub-critical water: Study of model compounds for food processing waste. J. Supercrit. Fluids 2017, 119, 26-35. [CrossRef]

45. Burns, F.P.; Themens, P.; Ghandi, K. Assessment of phosphonium ionic liquid- dimethylformamide mixtures for dissolution of cellulose. Compos. Interfaces 2013, 21, 59-73. [CrossRef]

46. Tan, Y.; Johnson, M.B.; Ghandi, K. Synthesis of Polypyrrole/ $\mathrm{TiO}_{2}$ Nanoparticles in Water by Chemical Oxidative Polymerization. In Biomaterial Aplications; Thomas, S., Nandhakumar, K., Weimen, Y., Babu, B.M., Eds.; Apple Academic Press: Palm Bay, FL, USA; Burlington, ON, Canada, 2014.

47. Troter, D.Z.; Todorović, Z.B.; Dokić-Stojanović, D.R.; Stamenković, O.S.; Veljković, V.B. Application of ionic liquids and deep eutectic solvents in biodiesel production: A review. Renew. Sustain. Energy Rev. 2016, 61, 473-500. [CrossRef]

48. Zhang, Z.; Song, J.; Han, B. Catalytic transformation of lignocellulose into chemicals and fuel products in ionic liquids. Chem. Rev. 2017, 117, 6834-6880. [CrossRef]

49. Zdanowicz, M.; Wilpiszewska, K.; Spychaj, T. Deep eutectic solvents for polysaccharides processing. A review. Carbohydr. Polym. 2018, 200, 361-380. [CrossRef]

50. Amiri, H.; Karimi, K. Pretreatment and hydrolysis of lignocellulosic wastes for butanol production: Challenges and perspectives. Bioresour. Technol. 2018, 270, 702-721. [CrossRef]

51. Lang, J.; Lu, J.; Lan, P.; Wang, N.; Yang, H.; Zhang, H. Preparation of 5-HMF in a DES/ethyl n-butyrate two-phase system. Catalysts 2020, 10, 636. [CrossRef]

52. Pham, T.N.; Sooknoi, T.; Crossley, S.P.; Resasco, D.E. Ketonization of carboxylic acids: Mechanisms, catalysts, and implications for biomass conversion. ACS Catal. 2013, 3, 2456-2473. [CrossRef]

53. Gilkey, M.J.; Xu, B. Heterogeneous catalytic transfer hydrogenation as an effective pathway in biomass upgrading. ACS Catal. 2016, 6, 1420-1436. [CrossRef]

54. Aitchison, H.; Wingad, R.L.; Wass, D.F. Homogeneous ethanol to butanol catalysis-Guerbet renewed. ACS Catal. 2016, 6, 7125-7132. [CrossRef]

55. Li, H.; Riisager, A.; Saravanamurugan, S.; Pandey, A.; Sangwan, R.S.; Yang, S.; Luque, R. Carbon-increasing catalytic strategies for upgrading biomass into energy-intensive fuels and chemicals. ACS Catal. 2018, 8, 148-187. [CrossRef]

56. Li, A.Y.; Moores, A. Carbonyl reduction and biomass: A case study of sustainable catalysis. ACS Sustain. Chem. Eng. 2019, 7, 10182-10197. [CrossRef]

57. Li, S.; Yu, D.; Cheng, S.; Cross, S.J. Recyclabl metal (Ni, Fe) cluster designed catalyst for cellulose pyrolysis to upgrade bio-oil. Catalysts 2020, 10, 1160. [CrossRef]

58. Traboni, S.; Bedini, E.; Vessella, G.; Iadonisi, A. Solvent-free approaches in carbohydrate synthetic chemistry: Role of catalysis in reactivity and selectivity. Catalysts 2020, 10, 1142. [CrossRef] 
59. Sun, L.; Wang, Z.; Chen, L.; Yang, S.; Xie, X.; Gao, M.; Zhao, B.; Si, H.; Li, J.; Hua, D. Catalytic fast pyrolysis of biomass into aromatic hydrocarbons over Mo-modified ZSM-5 catalysts. Catalysts 2020, 10, 1051. [CrossRef]

60. Al-sabawi, M.; Chen, J.; Ng, S. Fluid catalytic cracking of biomass-derived oils and their blends with petroleum feedstocks: A review. Energy Fuels 2012, 26, 5355-5372. [CrossRef]

61. Kostyniuk, A.; Grilc, M.; Likozar, B. Catalytic cracking of biomass-derived hydrocarbon tars or model compounds to form biobased benzene, toluene, and xylene isomer mixtures. Ind. Eng. Chem. Res. 2019, 58, 7690-7705. [CrossRef]

62. Chen, X.; Liu, Y.; Wang, J. Lignocellulosic biomass upgrading into valuable nitrogen- containing compounds by heterogeneous catalysts. Ind. Eng. Chem. Res. 2020, 59, 17008-17025. [CrossRef]

63. Liu, P.; Hao, J.W.; Mo, L.P.; Zhang, Z.H. Recent advances in the application of deep eutectic solvents as sustainable media as well as catalysts in. RSC Adv. 2015, 5, 48675-48704. [CrossRef]

64. Alhassan, Y.; Kumar, N. Single step biodiesel production from pongamia pinnata (Karanja) seed oil using deep eutectic solvent (DESs) catalysts. Waste Biomass Valorization 2016, 7, 1055-1065. [CrossRef]

65. Sert, M. Catalytic effect of acidic deep eutectic solvents for the conversion of levulinic acid to ethyl levulinate. Renew. Energy 2020, 153, 1155-1162. [CrossRef]

66. Liu, F.; Xue, Z.; Zhao, X.; Mou, H.; He, J.; Mu, T. Catalytic deep eutectic solvents for highly efficient conversion of cellulose to gluconic acid with gluconic acid self-precipitation separation. Chem. Commun. 2018, 54, 6140-6143. [CrossRef]

67. Long, T.; Deng, Y.; Gan, S.; Chen, J. Application of choline chloride $\times \mathrm{XnCl}_{2}$ ionic liquids for preparation of biodiesel. Chin. J. Chem. Eng. 2010, 18, 322-327. [CrossRef]

68. Mondal, D.; Sharma, M.; Wang, C.; Lin, Y.; Huang, H.; Saha, A.; Nataraj, S.K.; Prasad, K. Deep eutectic solvent promoted one step sustainable conversion of fresh seaweed biomass to functionalized graphene as a potential electrocatalyst. Green Chem. 2016, 18, 2819-2826. [CrossRef]

69. Hu, S.; Zhang, Z.; Zhou, Y.; Han, B.; Fan, H.; Li, W.; Song, J.; Xie, Y. Conversion of fructose to 5-hydroxymethylfurfural using ionic liquids prepared from renewable materials. Green Chem. 2008, 10, 1280-1283. [CrossRef]

70. Hu, S.; Zhang, Z.; Zhou, Y.; Song, J.; Fan, H.; Han, B. Direct conversion of inulin to 5-hydroxymethylfurfural in biorenewable ionic liquids. Green Chem. 2009, 11, 873-877. [CrossRef]

71. Zhang, L.; Yu, H. Conversion of xylan and xylose into furfural in biorenewable deep eutectic solvent with trivalent metal chloride added. BioResources 2013, 8, 6014-6025. [CrossRef]

72. Alvarez-Vasco, C.; Ma, R.; Quintero, M.; Guo, M.; Geleynse, S.; Ramasamy, K.K.; Wolcott, M.; Zhang, X. Unique low-molecularweight lignin with high purity extracted from wood by deep eutectic solvents (DES): A source of lignin for valorization. Green Chem. 2016, 18, 5133-5141. [CrossRef]

73. Yu, Q.; Zhang, A.; Wang, W.; Chen, L.; Bai, R.; Zhuang, X.; Wang, Q.; Wang, Z.; Yuan, Z. Deep eutectic solvents from hemicellulosederived acids for the cellulosic ethanol refining of Akebia' herbal residues. Bioresour. Technol. 2018, 247, 705-710. [CrossRef] [PubMed]

74. Shen, C.; Wang, X.; Zhu, Y.; Jiao, J.; Bao, S.; Kou, P.; Pan, H.; Li, Y.; Fu, Y. A green one-pot method for simultaneous extraction and transesterification of seed oil catalyzed by a p -toluenesulfonic acid based deep eutectic solvent. Ind. Crops Prod. 2020, $152,112517$. [CrossRef]

75. Zhang, H.; Yu, Z.; Gu, T.; Xiang, L.; Shang, M.; Shen, C.; Su, Y. Continuous synthesis of 5-hydroxymethylfurfural using deep eutectic solvents and its kinetic study in microreactors. Chem. Eng. J. 2020, 391, 123580. [CrossRef]

76. Alhassan, Y.; Kumar, N.; Bugaje, I.M. Catalytic upgrading of waste tire pyrolysis oil via supercritical esterification with deep eutectic solvents (green solvents and catalysts). J. Energy Inst. 2016, 89, 683-693. [CrossRef]

77. Song, X.; Hu, W.; Huang, W.; Wang, H.; Yan, S.; Yu, S. Methanolysis of polycarbonate into valuable product bisphenol A using choline chloride-based deep eutectic solvents as highly active catalysts. Chem. Eng. J. 2020, 388, 124324. [CrossRef]

78. Maka, H.; Spychaj, T.; Adamus, J. Lewis acid type deep eutectic solvents as catalysts for epoxy resin crosslinking. RSC Adv. 2015, 5, 82813-82821. [CrossRef]

79. Sirvio, J.A.; Heiskanen, J.P. Synthesis of alkaline-soluble cellulose methyl carbamate using reactive deep eutectic solvent. ChemSusChem 2017, 10, 455-460. [CrossRef]

80. Li, Z.; Long, J.; Zeng, Q.; Wu, Y.; Cao, M.; Liu, S.; Li, X. Production of methyl p-hydroxycinnamate by selective tailoring of herbaceous lignin using metal-based deep eutectic solvents (DES) as catalyst. Ind. Eng. Chem. Res. 2020, 59, 17328-17337. [CrossRef]

81. Liu, B.; Fu, W.; Lu, X.; Zhou, Q.; Zhang, S. Lewis acid-base synergistic catalysis for polyethylene terephthalate degradation by 1,3-dimethylurea/Zn(OAc) 2 deep eutectic solvent. Sustain. Chem. Eng. 2019, 7, 3292-3300. [CrossRef]

82. Yang, X.; Xie, H.; Du, H.; Zhang, X.; Zou, Z.; Zou, Y.; Liu, W.; Lan, H.; Zhang, X.; Si, C. Facile extraction of thermally stable and dispersible cellulose nanocrystals with high yield via a green and recyclable $\mathrm{FeCl}_{3}$-catalyzed deep eutectic solvent system. ACS Sustain. Chem. Eng. 2019, 7, 7200-7208. [CrossRef]

83. Bu, C.; Yan, Y.; Zou, L.; Ouyang, S.; Zheng, Z. Comprehensive utilization of corncob for furfuryl alcohol production by chemo-enzymatic sequential catalysis in a biphasic system. Bioresour. Technol. 2021, 319, 124156. [CrossRef]

84. Li, L.; Wu, Z.; Xi, X.; Liu, B.; Cao, Y.; Xu, H.; Hu, Y. A bifunctional brønsted acidic deep eutectic solvent to dissolve and catalyze the depolymerization of alkali lignin. J. Renew. Mater. 2021, 9, 219-235. [CrossRef] 
85. Hayyan, A.; Ali Hashim, M.; Mjalli, F.S.; Hayyan, M.; AlNashef, I.M. A novel phosphonium-based deep eutectic catalyst for biodiesel production from industrial low grade crude palm oil. Chem. Eng. Sci. 2013, 92, 81-88. [CrossRef]

86. Hayyan, A.; Hashim, M.A.; Hayyan, M.; Mjalli, F.S.; Alnashef, I.M. A novel ammonium based eutectic solvent for the treatment of free fatty acid and synthesis of biodiesel fuel. Ind. Crops Prod. 2013, 46, 392-398. [CrossRef]

87. Hayyan, A.; Ali, M.; Hayyan, M.; Mjalli, F.S.; Alnashef, I.M. A new processing route for cleaner production of biodiesel fuel using a choline chloride based deep eutectic solvent. J. Clean. Prod. 2014, 65, 246-251. [CrossRef]

88. Zhang, L.; Yu, H.; Yu, H.; Chen, Z.; Yang, L. Conversion of xylose and xylan into furfural in biorenewable choline chloride-oxalic acid deep eutectic solvent with the addition of metal chloride. Chin. Chem. Lett. 2014, 25, 1132-1136. [CrossRef]

89. Assanosi, A.A.; Farah, M.M.; Wood, J.; Al-duri, B. A facile acidic choline chloride-p-TSA DES catalysed dehydration of fructose to 5-hydroxymethylfurfural. RSC Adv. 2014, 4, 39359-39364. [CrossRef]

90. Assanosi, A.; Farah, M.M.; Wood, J.; Al-duri, B. Fructose dehydration to 5HMF in a green self-catalysed DES composed of N,N-diethylethanolammonium chloride and p-toluenesulfonic acid monohydrate (p-TSA). C. R. Chim. 2016, 19, 450-456. [CrossRef]

91. Williamson, S.T.; Shahbaz, K.; Mjalli, F.S.; Alnashef, I.M.; Farid, M.M. Application of deep eutectic solvents as catalysts for the esterification of oleic acid with glycerol. Renew. Energy 2017, 114, 480-488. [CrossRef]

92. Gawade, A.B.; Yadav, G.D. Microwave assisted synthesis of 5-ethoxymethylfurfural in one pot from D-fructose by using deep eutectic solvent as catalyst under mild condition. Biomass Bioenergy 2018, 117, 38-43. [CrossRef]

93. Bodachivskyi, I.; Kuzhiumparambil, U.; Williams, D.B.G. High yielding acid-catalysed hydrolysis of cellulosic polysaccharides and native biomass into low molecular weight sugars in mixed ionic liquid systems. ChemistryOpen 2019, 8, 1316-1324. [CrossRef] [PubMed]

94. Arslanoğlu, A.; Sert, M. Direct conversion of biomass to platform chemicals, catalyzed using a deep eutectic solvent of N,N diethyl ethanol ammonium chloride-oxalic acid in a microwave reactor. Fuel 2019, 258, 116142. [CrossRef]

95. Yu, F.L.; Gu, Y.L.; Gao, X.; Liu, Q.C.; Xie, C.X.; Yu, S.T. Alkylation of isobutane and isobutene catalyzed by trifluoromethanesulfonic acid-taurine deep eutectic solvents in polyethylene glycol. Chem. Commun. 2019, 55, 4833-4836. [CrossRef] [PubMed]

96. Smink, D.; Juan, A.; Schuur, B.; Kersten, S.R.A. Understanding the role of choline chloride in deep eutectic solvents used for biomass delignification. Ind. Eng. Chem. Res. 2019, 58, 16348-16357. [CrossRef]

97. Morais, E.S.; Freire, M.G.; Freire, C.S.R.; Coutinho, J.A.P.; Silvestre, A.J.D. Enhanced conversion of xylan into furfural using acidic deep eutectic solvents with dual solvent and catalyst behavior. ChemSusChem 2020, 13, 784-790. [CrossRef]

98. Razavian, M.; Fatemi, S. Intensified transformation of low-value residual fuel oil to light fuels with TPABr:EG as deep eutectic solvent with dual functionality at moderate temperatures. Energy Fuels 2020, 34, 5497-5510. [CrossRef]

99. Zhang, D.; Chen, X.; Yuan, B.; Yu, F.; Xie, C.; Yu, S. A novel green catalytic strategy for hydration of $\alpha$-pinene by a natural deep eutectic solvent. Biomass Convers. Biorefin. 2020. [CrossRef]

100. Lopes, A.M.D.; Gomes, J.R.B.; Coutinho, J.A.P.; Silvestre, A.J.D. Novel insights into biomass delignification with acidic deep eutectic solvents: A mechanistic study of $\beta-\mathrm{O}-4$ ether bond cleavage and the role of the halide counterion in the catalytic performance. Green Chem. 2020, 22, 2474-2487. [CrossRef]

101. Ruan, C.; Mo, F.; Qin, H.; Cheng, H.; Chen, L.; Qi, Z. Bifunctional imidazole-benzenesulfonic acid deep eutectic solvent for fructose dehydration to 5-hydroxymethylfurfural. Catal. Lett. 2020. [CrossRef]

102. Zhang, T.; Shahbaz, K.; Farid, M.M. Glycerolysis of free fatty acid in vegetable oil deodorizer distillate catalyzed by phosphoniumbased deep eutectic solvent. Renew. Energy 2020, 160, 363-373. [CrossRef]

103. Wang, H.; Li, J.; Zeng, X.; Tang, X.; Sun, Y.; Lei, T.; Lin, L. Extraction of cellulose nanocrystals using a recyclable deep eutectic solvent. Cellulose 2020, 27, 1301-1314. [CrossRef]

104. Liu, Y.; Wang, Y.; Cao, Y.; Chen, X.; Yu, Q.; Wang, Z.; Yuan, Z. One-pot synthesis of cyclic biofuel intermediates from biomass in choline chloride/formic acid-based deep eutectic solvents. ACS Sustain. Chem. Eng. 2020, 8, 6949-6955. [CrossRef]

105. Wang, S.; Li, H.; Xiao, L.; Song, G. Unraveling the structural transformation of wood lignin during deep eutectic solvent treatment. Front. Energy Res. 2020, 8, 48. [CrossRef]

106. Shen, X.; Chen, T.; Wang, H.; Mei, Q.; Yue, F.; Sun, S.; Wen, J.-L.; Yuan, T.-Q.; Sun, R.-C. Structural and morphological transformations of lignin macromolecules during bio-based deep eutectic solvent (DES) pretreatment. ACS Sustain. Chem. Eng. 2020, 8, 2130-2137. [CrossRef]

107. Guo, D.; Guo, Y.; Sha, L.; Lyu, G.; Li, J.; Zhang, X.; Liu, B. Subcritical ethanol catalyzed with deep eutectic solvent extract phenolic lignin for preparation of an ultraviolet-blocking composite film. Energy Fuels 2020, 34, 8395-8402. [CrossRef]

108. Jiang, J.; Carrillo-Enriquez, N.C.; Oguzlu, H.; Han, X.; Bi, R.; Song, M.; Saddler, J.N.; Sun, R.; Jiang, F. High production yield and more thermally stable lignin-containing cellulose nanocrystals isolated using a ternary acidic deep eutectic solvent. ACS Sustain. Chem. Eng. 2020, 8, 7182-7191. [CrossRef]

109. Bodachivskyi, I.; Kuzhiumparambil, U.; Williams, D.B.G. Catalytic valorization of native biomass in a deep eutectic solvent: A systematic approach toward high-yielding reactions of polysaccharides. ACS Sustain. Chem. Eng. 2020, 8, 678-685. [CrossRef]

110. Tian, D.; Guo, Y.; Hu, J.; Yang, G.; Zhang, J.; Luo, L.; Xiao, Y.; Deng, S.; Deng, O.; Zhou, W.; et al. Acidic deep eutectic solvents pretreatment for selective lignocellulosic biomass fractionation with enhanced cellulose reactivity. Int. J. Biol. Macromol. 2020, 142, 288-297. [CrossRef] 
111. Liu, Y.; Yan, H.; Liu, J.; Dong, W.; Cao, Z.; Hu, X.; Zhou, Z. Acidic deep eutectic solvents with long carbon chains as catalysts and reaction media for biodiesel production. Renew. Energy 2020, 162, 1842-1853. [CrossRef]

112. Xu, H.; Kong, Y.; Peng, J.; Song, X.; Liu, Y.; Su, Z.; Li, B.; Gao, C.; Tian, W. Comprehensive analysis of important parameters of choline chloride-based deep eutectic solvent pretreatment of lignocellulosic biomass. Bioresour. Technol. 2021, $319,124209$. [CrossRef] [PubMed]

113. Samaranayake, C.P.; Sastry, S.K. In-situ pH measurement of selected liquid foods under high pressure. Innov. Food Sci. Emerg. Technol. 2013, 17, 22-26. [CrossRef]

114. Taysun, M.B.; Sert, E.; Atalay, F.S. Physical properties of benzyl tri-methyl ammonium chloride based deep eutectic solvents and employment as catalyst. J. Mol. Liq. 2016, 223, 845-852. [CrossRef]

115. Sun, J.; Bostick, B.C.; Mailloux, B.J.; Ross, J.M.; Chillrud, S.N. Effect of oxalic acid treatment on sediment arsenic concentrations and lability under reducing conditions. J. Hazard. Mater. 2016, 311, 125-133. [CrossRef] [PubMed]

116. Miyaji, H.; Fujimoto, J.; Mabuchi, R.; Okumura, M.; Goto, S.; Honda, Y. A novel anthracene-based fluorescent colorimetric sensor for the simple naked-eye diagnosis of methylmalonic aciduria. Tetrahedron Lett. 2017, 58, 3623-3627. [CrossRef]

117. Eda, S.; Borra, A.; Parthasarathy, R.; Bankupalli, S.; Bhargava, S.; Thella, P.K. Recovery of levulinic acid by reactive extraction using tri-n-octylamine in methyl isobutyl ketone: Equilibrium and thermodynamic studies and optimization using Taguchi multivariate approach. Sep. Purif. Technol. 2018, 197, 314-324. [CrossRef]

118. Cecchin, D.; Bringhenti, I.L.; Bernardi, J.B.; Leal, L.O.; Souza, M.A.; Bedran-Russo, A.K.; Farina, A.P. Alpha-hydroxy glycolic acid for root dentin etching: Morphological analysis and push out bond strength. Int. J. Adhes. Adhes. 2019, 90, 138-143. [CrossRef]

119. Zhang, M.; Wei, Z.; Chen, W.; Xu, M.; Cai, J.; Chen, Y. Bell shape vs volcano shape pH dependent kinetics of the electrochemical oxidation of formic acid and formate, intrinsic kinetics or local pH shift? Electrochim. Acta 2020, 363, 137160. [CrossRef]

120. Kumar, N.; Gautam, R.; Stallings, J.D.; Coty, G.G.; Lynam, J.G. Secondary agriculture residues pretreatment using deep eutectic solvents. Waste Biomass Valorization 2020. [CrossRef]

121. Wang, Z.; Hong, S.; Wen, J.; Ma, C.Y.; Tang, L.; Jiang, H.; Chen, J.; Li, S.; Shen, X.; Yuan, T. Lewis acid-facilitated deep eutectic solvent (DES) pretreatment for producing high-purity and antioxidative lignin. ACS Sustain. Chem. Eng. 2020, 8, $1050-1057$. [CrossRef]

122. Teles, A.R.R.; Capela, E.V.; Carmo, R.S.; Coutinho, J.A.P.; Silvestre, A.J.D.; Freire, M.G. Solvatochromic parameters of deep eutectic solvents formed by ammonium-based salts and carboxylic acids. Fluid Phase Equilibria 2017, 448, 15-21. [CrossRef] [PubMed]

123. Abbott, A.P.; Alabdullah, S.S.M.; Al-murshedi, A.Y.M.; Ryder, K.S. Brønsted acidity in deep eutectic solvents and ionic liquids. Faraday Discuss. 2018, 206, 365-377. [CrossRef]

124. Hou, X.; Li, A.; Lin, K.; Wang, Y.; Kuang, Z.; Cao, S. Insight into the structure-function relationships of deep eutectic solvents during rice straw pretreatment. Bioresour. Technol. 2018, 249, 261-267. [CrossRef] [PubMed]

125. Tan, Y.T.; Ngoh, G.C.; Seak, A.; Chua, M. Effect of functional groups in acid constituent of deep eutectic solvent for extraction of reactive lignin. Bioresour. Technol. 2019, 281, 359-366. [CrossRef] [PubMed]

126. Ma, F.; Hanna, M.A. Biodiesel production: A review. Bioresour. Technol. 1999, 70, 1-15. [CrossRef]

127. Atadashi, I.M.; Aroua, M.K.; Aziz, A.R.A.; Sulaiman, N.M.N. The effects of catalysts in biodiesel production: A review. J. Ind. Eng. Chem. 2013, 19, 14-26. [CrossRef]

128. Li, H.; Saravanamurugan, S.; Yang, S.; Riisager, A. Direct transformation of carbohydrates to the biofuel 5-ethoxymethylfurfural by solid acid catalysts. Green Chem. 2016, 18, 726-734. [CrossRef]

129. Vardon, D.R.; Sharma, B.K.; Scott, J.; Yu, G.; Wang, Z.; Schideman, L.; Zhang, Y.; Strathmann, T.J. Chemical properties of biocrude oil from the hydrothermal liquefaction of Spirulina algae, swine manure, and digested anaerobic sludge. Bioresour. Technol. 2011, 102, 8295-8303. [CrossRef]

130. Faeth, J.L.; Valdez, P.J.; Savage, P.E. Fast hydrothermal liquefaction of nannochloropsis sp. to produce biocrude. Energy Fuels 2013, 27, 1391-1398. [CrossRef]

131. Li, X.; Xu, R.; Yang, J.; Nie, S.; Liu, D.; Liu, Y.; Si, C. Production of 5-hydroxymethylfurfural and levulinic acid from lignocellulosic biomass and catalytic upgradation. Ind. Crops Prod. 2019, 130, 184-197. [CrossRef]

132. Zuo, M.; Le, K.; Li, Z.; Jiang, Y.; Zeng, X.; Tang, X.; Sun, Y.; Lin, L. Green process for production of 5-hydroxymethylfurfural from carbohydrates with high purity in deep eutectic solvents. Ind. Crops Prod. 2017, 99, 1-6. [CrossRef]

133. Werpy, T.; Petersen, G.; Aden, A.; Bozel, J.; Holladay, J.; White, J.; Manheim, A. Top Value Added Chemicals from Biomass Volume I-Results of Screening for Potential Candidates from Sugars and Synthesis Gas; National Renewable Energy Lab.: Golden, CO, USA, 2004.

134. Rinaldi, R.; Schuth, F. Design of solid catalysts for the conversion of biomass. Energy Environ. Sci. 2009, 2, 610-626. [CrossRef]

135. Dhepe, P.L.; Sahu, R. A solid-acid-based process for the conversion of hemicellulose. Green Chem. 2010, 12, 2153-2156. [CrossRef]

136. Yu, Q.; Qin, L.; Liu, Y.; Sun, Y.; Xu, H.; Wang, Z. In situ deep eutectic solvent pretreatment to improve lignin removal from garden wastes and enhance production of bio-methane and microbial lipids. Bioresour. Technol. 2019, 271, 210-217. [CrossRef]

137. Liu, Y.; Chen, W.; Xia, Q.; Guo, B.; Wang, Q.; Liu, S. Efficient cleavage of lignin-carbohydrate complexes and ultrafast extraction of lignin oligomers from wood biomass by microwave-assisted treatment with deep eutectic solvent. ChemSusChem 2017, 10, 1692-1700. [CrossRef] 
138. Zhenquan, V.; Yeong, T.; Basil, C.; Loong, T.; Wei, N.; Cheong, R.; Pui, K.; Shak, Y. Ultrasonics-Sonochemistry Sequential ultrasonication and deep eutectic solvent pretreatment to remove lignin and recover xylose from oil palm fronds. Ultrason. Sonochem. 2019, 58, 104598

139. Chen, Y.; Zhang, L.; Yu, J.; Lu, Y.; Jiang, B.; Fan, Y.; Wang, Z. High-purity lignin isolated from poplar wood meal through dissolving treatment with deep eutectic solvents. R. Soc. Open Sci. 2019, 6, 181757. [CrossRef]

140. Loow, Y.L.; New, E.K.; Yang, G.H.; Ang, L.Y.; Foo, L.Y.W.; Wu, T.Y. Potential use of deep eutectic solvents to facilitate lignocellulosic biomass utilization and conversion. Cellulose 2017, 24, 3591-3618. [CrossRef]

141. Abbott, A.P.; Cullis, P.M.; Gibson, M.J.; Harris, R.C.; Raven, E. Extraction of glycerol from biodiesel into a eutectic based ionic liquid. Green Chem. 2007, 9, 868-872. [CrossRef]

142. Hayyan, M.; Mjalli, F.S.; Hashim, M.A.; AlNashef, I.M. A novel technique for separating glycerine from palm oil-based biodiesel using ionic liquids. Fuel Process. Technol. 2010, 91, 116-120. [CrossRef]

143. Dai, Y.; Witkamp, G.J.; Verpoorte, R.; Choi, Y.H. Natural deep eutectic solvents as a new extraction media for phenolic metabolites in Carthamus tinctorius L. Anal. Chem. 2013, 85, 6272-6278. [CrossRef] [PubMed]

144. Vigier, K.D.O.; Chatel, G.; Fran, Å. Contribution of deep eutectic solvents for biomass processing: Opportunities, challenges, and limitations. ChemCatChem 2015, 7, 1250-1260. [CrossRef]

145. Chen, Y.; Yu, D.K.; Chen, W.J.; Fu, L.; Mu, T.C. Water absorption by deep eutectic solvents. Phys. Chem. Chem. Phys. 2019, 21, 2601-2610. [CrossRef] [PubMed]

146. Procentese, A.; Johnson, E.; Orr, V.; Garruto, A.; Wood, J.A.; Marzocchella, A.; Rehmann, L. Deep eutectic solvent pretreatment and subsequent saccharification of corncob. Bioresour. Technol. 2015, 192, 31-36. [CrossRef] [PubMed] 